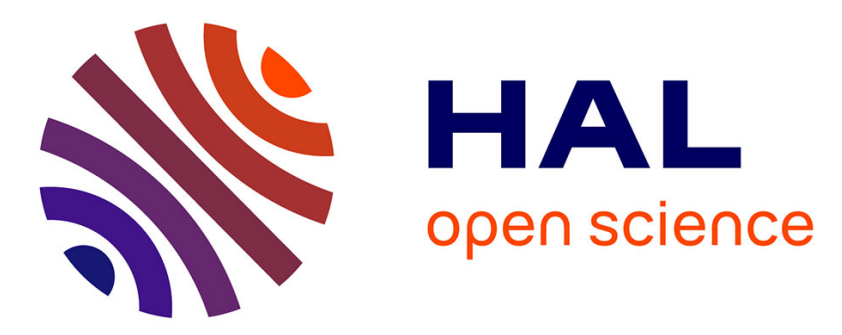

\title{
Hexalanthanide Complexes as Molecular Precursors: Synthesis, Crystal Structure, and Luminescent and Magnetic Properties
}

Haiyun Yao, Guillaume Calvez, Carole Daiguebonne, Kevin Bernot, Yan Suffren, Marin Puget, Christophe Lescop, Olivier Guillou

\section{To cite this version:}

Haiyun Yao, Guillaume Calvez, Carole Daiguebonne, Kevin Bernot, Yan Suffren, et al.. Hexalanthanide Complexes as Molecular Precursors: Synthesis, Crystal Structure, and Luminescent and Magnetic Properties. Inorganic Chemistry, 2017, 56 (23), pp.14632-14642. 10.1021/acs.inorgchem.7b02452 . hal-01657831

\section{HAL Id: hal-01657831 https://hal.science/hal-01657831}

Submitted on 9 Mar 2018

HAL is a multi-disciplinary open access archive for the deposit and dissemination of scientific research documents, whether they are published or not. The documents may come from teaching and research institutions in France or abroad, or from public or private research centers.
L'archive ouverte pluridisciplinaire HAL, est destinée au dépôt et à la diffusion de documents scientifiques de niveau recherche, publiés ou non, émanant des établissements d'enseignement et de recherche français ou étrangers, des laboratoires publics ou privés. 


\section{Hexa-lanthanide complexes as molecular precursors: synthesis, crystal structure, luminescent and magnetic properties.}

Haiyun Yao, Guillaume Calvez*, Carole Daiguebonne, Kevin Bernot, Yan Suffren, Marin Puget, Christophe Lescop and Olivier Guillou*.

INSA Rennes, UMR CNRS 6226 "Institut des Sciences Chimiques de Rennes", 20 Avenue des buttes de Coesmes, F-35708, Rennes.

* To whom correspondence should be addressed. 
ABSTRACT.

Reaction of hexa-nuclear octahedral molecular precursors with 3-chlorobenzoate ligand affords an unprecedented family of iso-structural poly-lanthanide complexes via solvo-thermal and microwaves assisted syntheses in acetonitrile medium. General chemical formula of the compounds that constitute this series is $\left\{\left[\mathrm{Ln}_{6}\left(\mu_{3}-\mathrm{OH}\right)_{2}\left(\mathrm{H}_{2} \mathrm{O}\right)_{2}\left(\mathrm{NO}_{3}\right)_{2}(\mathbf{3}-\mathbf{c b})_{14}\right] \cdot\left(\mathrm{CH}_{3} \mathrm{CN}\right)_{4}\right\}$ where 3-cb' stands for 3-chlorobenzoate and $\mathrm{Ln}=\mathrm{Eu}, \mathrm{Tb}, \mathrm{Dy}, \mathrm{Ho}, \mathrm{Er}$ plus Y. Crystal structure, solubility, magnetic and luminescent properties of these complexes have been studied. Luminescence properties evidence that the composition of the hexa-lanthanide precursor is preserved upon the synthetic process that is of particular interest as far as hetero-lanthanide complexes are targeted. 


\section{INTRODUCTION.}

For more than a decade, there is a growing interest for lanthanide-based coordination compounds because of their potential applications in various fields such as imaging, ${ }^{[1-2]}$ display, ${ }^{[3-4]}$ lighting $^{[5-6]}$ or fight against counterfeiting. ${ }^{[7-8]}$ Indeed, lanthanide ions present long luminescent lifetimes and luminescence color purity that make them promising candidates for optical applications. Because of their shielded $4 \mathrm{f}$ valence orbitals they present almost no sensibility to crystal field ${ }^{[9-10]}$ nor size dependent effects. ${ }^{[1-12]}$ Therefore, most of the works reported to date have focused their attention on the choice of the ligands and their ability for acting as efficient antenna ${ }^{[13]}$ towards lanthanide ions. As a consequence, compared with transition metal ions-based coordination compounds, ${ }^{[14-17]}$ examples of poly-lanthanide coordination compounds are less common.

For many years, our group is involved in a research project that deals with the synthesis of oxo-hydroxo poly-lanthanide complexes that are usable as molecular building blocks for the design of new coordination compounds with unprecedented physical properties. ${ }^{[18]}$ To date, numerous coordination compounds with oxo-hydroxo cores have been reported ${ }^{[19]}$ but most of them have been obtained by one-pot synthesis from simple lanthanide salts or oxides. ${ }^{[20-21]}$ So far, only two families of compounds have been obtained from previously synthesized and isolated oxo-hydroxo poly-lanthanide complexes starting reagents. ${ }^{[22-24]}$ Compounds that constitute the first family can be described as $1 \mathrm{D}$ molecular chains in which hexa-lanthanide complexes are bound to each other by terephthalate ions. ${ }^{[24]}$ Compounds of the second series are nano-aggregates dispersed in poly-ol media of the hexa-lanthanide complexes themselves. ${ }^{[22]}$ Both families have been obtained from octahedral hexa-lanthanide complexes that had been previously synthesized according to the so-called "direct hydrolysis strategy". ${ }^{[25-26]}$ We want to report here the first series of discrete complexes 
obtained by using previously isolated hexa-lanthanide complexes as molecular building blocks.

\section{EXPERIMENTAL SECTION.}

\section{Synthesis.}

Lanthanide oxides 4N were purchased from AMPERE and 3-chlorobenzoic acid from TCI. Both were used without further purification. Starting octahedral hexa-lanthanide complexes, with general chemical formula $\left[\operatorname{Ln}_{6}\left(\mu_{6}-\mathrm{O}\right)\left(\mu_{3}-\mathrm{OH}\right)_{8}\left(\mathrm{NO}_{3}\right)_{6}\left(\mathrm{H}_{2} \mathrm{O}\right)_{12}\right] \cdot 2 \mathrm{NO}_{3} \cdot 2 \mathrm{H}_{2} \mathrm{O}$ where $\mathrm{Ln}=\mathrm{Sm}-\mathrm{Lu}$ plus $\mathrm{Y}($ Figure 1$)$, hereafter symbolized by $\left[\mathbf{L} \mathbf{n}_{\mathbf{6}}\right]$, were synthesized according to previously published procedures. ${ }^{[26]}$ Purity of the micro-crystalline powders was controlled by powder X-ray diffraction (diagrams have been collected using a Panalytical $\mathrm{X}^{\prime}$ Pert Pro diffractometer equipped with an $\mathrm{X}^{\prime}$ Celerator detector).

Iso-structural

hetero-nuclear

complexes,

$\left[\operatorname{Ln}_{6-6 x} \mathrm{Ln}_{6 \mathrm{x}}^{\prime}\left(\mu_{6}-\mathrm{O}\right)\left(\mu_{3}-\mathrm{OH}\right)_{8}\left(\mathrm{NO}_{3}\right)_{6}\left(\mathrm{H}_{2} \mathrm{O}\right)_{12}\right] \cdot 2 \mathrm{NO}_{3} \cdot 2 \mathrm{H}_{2} \mathrm{O}, \quad$ hereafter $\quad$ symbolized by [Ln $\left.\mathbf{L n}_{\mathbf{6}-\mathbf{x}} \mathbf{L n}_{6 \mathbf{6 x}}\right]$, were obtained according to similar procedures by using the appropriate mixture of lanthanide nitrate solutions in the synthesis. ${ }^{[23]}$ Ratios between the two different lanthanide ions were controlled by SEM measurements (Hitachi TM-1000, Tabletop Microscope version 02.11 with EDS analysis system).

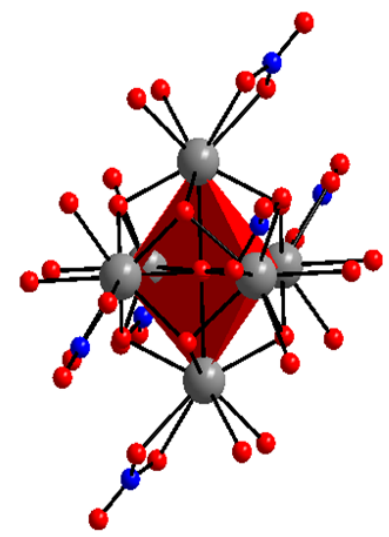

Figure 1. Projection view of the molecular motif of [Dy $\mathbf{y}_{\mathbf{6}}$. Redrawn from reference. ${ }^{[18]}$ 


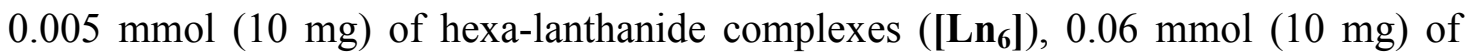
3-chlorobenzoic acid (hereafter symbolized by $\mathrm{H}_{2}(\mathbf{3}-\mathbf{c b})$ ) and $2 \mathrm{~mL}$ of acetonitrile were put in $24 \mathrm{~mL}$ Parr autoclaves. Parr autoclaves were heated between $60^{\circ} \mathrm{C}$ and $120^{\circ} \mathrm{C}$, depending on the involved lanthanide ion, during 100 hours. Then autoclaves were cooled down at a cooling rate of $2^{\circ} \mathrm{C}$ per hour. Resulting clear solutions were then left for a few days at room temperature in closed vessels. After few days, single crystals appeared (Figure 2). They were filtered, washed with acetonitrile and dried at ambient air. The experimental details for each lanthanide ion are listed in Table 1. From this table, it can be noticed that the smaller is the lanthanide ion, the higher is the temperature of synthesis and the longer is the time required for crystallization. This may be related to the bigger stability of the hexa-lanthanide complexes that involve the smallest lanthanide ions. ${ }^{[23]}$ Iso-structurality of the different compounds has been assumed on the basis of their unit cell determination. Their general chemical formula is $\left\{\left[\mathrm{Ln}_{6}\left(\mu_{3}-\mathrm{OH}\right)_{2}\left(\mathrm{H}_{2} \mathrm{O}\right)_{2}\left(\mathrm{NO}_{3}\right)_{2}(3-\mathbf{c b})_{14}\right] \cdot\left(\mathrm{CH}_{3} \mathrm{CN}\right)_{4}\right\}$ with $\mathrm{Ln}=\mathrm{Eu}, \mathrm{Tb}$, Dy, Ho, Er or Y, hereafter symbolized by $\left\{\mathbf{L n}_{6}(\mathbf{3}-\mathbf{c b})\right\}$.

\begin{tabular}{ccc}
\hline \multicolumn{2}{c}{ Table 1. Details for the syntheses of $\left\{\mathbf{L n}_{\mathbf{6}}(\mathbf{3}-\mathbf{c b})\right\}$ with $\mathrm{Ln}=\mathrm{Eu}, \mathrm{Tb}, \mathrm{Dy}, \mathrm{Ho}, \mathrm{Er}$ or $\mathrm{Y}}$. \\
\hline Lanthanide ion & Temperature range $\left({ }^{\circ} \mathrm{C}\right)$ & Crystallization time \\
\hline $\mathrm{Eu}^{3+}$ & $60-70$ & 3 days \\
$\mathrm{Tb}^{3+}$ & $60-80$ & 3 days \\
$\mathrm{Dy}^{3+}$ & $70-90$ & 5 days \\
$\mathrm{Ho}^{3+}$ & $80-120$ & 5 days \\
$\mathrm{Er}^{3+}$ & $80-130$ & 5 days \\
$\mathrm{Y}^{3+}$ & $80-100$ & 5 days \\
\hline
\end{tabular}

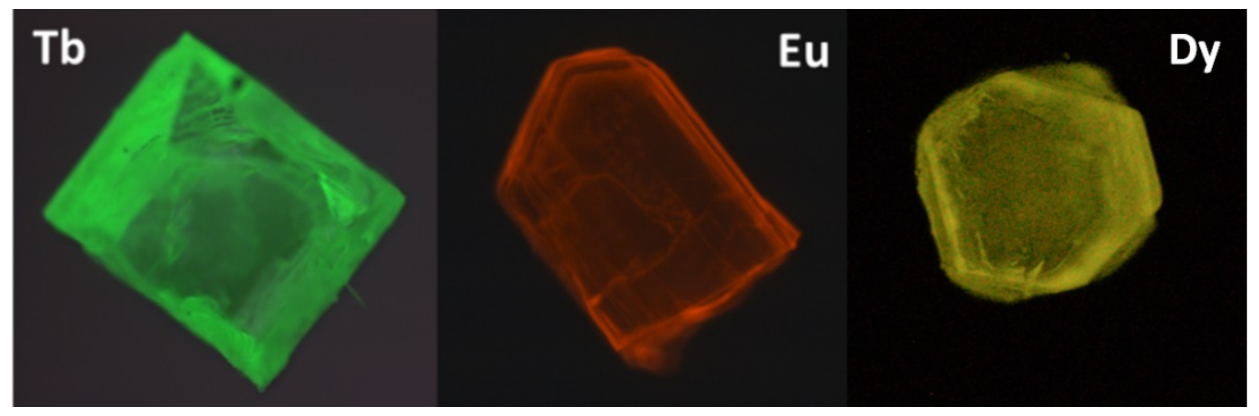

Figure 2. Pictures under UV-irradiation $\left(\lambda_{\mathrm{exc}}=312 \mathrm{~nm}\right)$ of $\left\{\mathbf{L n}_{\mathbf{6}}(\mathbf{3}-\mathbf{c b})\right\}$ with $\mathrm{Ln}=\mathrm{Tb}$ (left, green crystal), Eu (middle, red crystal) and Dy (right, yellow crystal). 
Each batch produces only few crystals: about $150 \mu \mathrm{g}$ per autoclaves (average over 20 identical autoclaves). Moreover, the synthetic process is quite long (comprised between seven and nine days) and despite great synthetic effort, we did not succeed in obtaining microcrystalline powders in high yields. The low yield and long-time reaction has encouraged us to reduce the synthetic duration by using microwaves assisted synthesis $\left(\mathrm{T}=100{ }^{\circ} \mathrm{C} ; \mathrm{P}=2\right.$ bar; Power $=150 \mathrm{~W}$; duration $=30 \mathrm{~min}$; crystallization time $=3$ days $)$.

\section{Single crystal X-ray diffraction.}

Single crystal of $\left\{\mathbf{D y}_{\mathbf{6}} \mathbf{( 3 - \mathbf { c b } ) \}}\right.$ was mounted on a D8Venture Bruker AXS diffractometer $(150 \mathrm{~K})$ with $\mathrm{Mo} \mathrm{K}_{\alpha}$ radiation $(\lambda=0.71073 \AA)$ and equipped with a CMOS PHOTON100 detector. Data reduction and cell refinement were performed with Apex3 (2015), Saint (V8.37a) and Sadabs (2014/5). ${ }^{[27-29]}$ The crystal structure has been solved by direct methods using SIR97 program, ${ }^{[30]}$ and refined with full matrix least-square methods based on $\mathrm{F}^{2}$ (SHELX97 ${ }^{[31]}$ ) with WINGX program. ${ }^{[32]}$ All non-hydrogen atoms were refined anisotropically using SHELXL program. Hydrogen atoms bound to the organic ligand were located at ideal positions. Hydrogen atoms of the water or acetonitrile molecules were not located. Crystal and final structure refinement data of $\left\{\mathbf{D y}_{\mathbf{6}}(\mathbf{3}-\mathbf{c b})\right\}$ are listed in Table 2. Full details of the X-ray structure determination of the crystal structure have been deposited at the Cambridge Crystallographic Data Center under the depository number CCDC-1571385. They can be obtained free of charge at http://www.ccdc.cam.ac.uk/conts/retrieving.html [or from the Cambridge Crystallographic Data Centre, 12, Union Road, Cambridge CB2 IEZ, UK; fax: (internat.) +44-1223/336-033; E-mail: deposit@ccdc.cam.ac.uk], on request, from the authors and the reference to this publication. 


\begin{tabular}{llll}
\hline \multicolumn{4}{l}{ Table 2. Crystal and final structure refinement data for $\left\{\mathbf{D \mathbf { y } _ { 6 }} \mathbf{( 3 - c b )}\right\}$. } \\
\hline Molecular formula & $\mathrm{C}_{106} \mathrm{H}_{74} \mathrm{Cl}_{14} \mathrm{Dy}_{6} \mathrm{~N}_{6} \mathrm{O}_{38}$ & Formula weight $\left(\mathrm{g} \cdot \mathrm{mol}^{-1}\right)$ & 3511 \\
Asymmetric unit & $\mathrm{C}_{53} \mathrm{H}_{37} \mathrm{Cl}_{7} \mathrm{Dy}_{3} \mathrm{~N}_{3} \mathrm{O}_{19}$ & Space group (No.) & $P-1(2)$ \\
System & triclinic & $\alpha\left(^{\circ}\right)$ & $102.844(4)$ \\
$a(\AA)$ & $13.9825(17)$ & $\beta\left(^{\circ}\right)$ & $108.306(4)$ \\
$b(\AA)$ & $16.5065(19)$ & $\gamma\left(^{\circ}\right)$ & $111.950(4)$ \\
$c(\AA)$ & $17.3472(18)$ & $Z$ & 2 \\
$V\left(\AA^{3}\right)$ & $3252.7(7)$ & $\mu\left(\mathrm{mm}^{-1}\right)$ & 3.766 \\
$D_{\text {calc }}\left(\mathrm{g}^{\circ} \mathrm{cm}^{-3}\right)$ & 1.792 & $R_{W}(\%)$ & 14.14 \\
$R(\%)$ & 4.70 & $\mathrm{~N}^{\circ} \mathrm{CCDC}$ & 1571385 \\
GoF & 1.052 & & \\
\hline
\end{tabular}

\section{FT-IR spectra.}

FT-IR spectra of $\left\{\mathbf{L n}_{\mathbf{6}}(\mathbf{3}-\mathbf{c b})\right\}$ with $\mathrm{Ln}=\mathrm{Eu}$, Dy and Y were obtained from solid samples with a Perkin Elmer Frontier FT-IR spectrometer equipped with a MIR-ATR module between $4000 \mathrm{~cm}^{-1}$ and $650 \mathrm{~cm}^{-1}$. All spectra show the characteristic band for deprotonated carboxylato groups (1380 and $\left.1590 \mathrm{~cm}^{-1}\right)$, for nitrato groups $\left(1360\right.$ and $\left.1550 \mathrm{~cm}^{-1}\right)$ and for acetonitrile $\left(2260 \mathrm{~cm}^{-1}\right)$ and finally for $\mu_{3}-\mathrm{OH}$ and water groups (broad band at $3350 \mathrm{~cm}^{-1}$ ) which is in good agreement with the crystal structure (See Figure S1).

\section{UV-visible absorption spectra.}

UV-vis absorption spectra have been recorded on a Perkin-Elmer Lambda 650 spectrometer. Because small quantities of single crystals are difficult to precisely weight, we have estimated the concentration of the solutions by application of the so-called "Beer-Lambert law":

$$
A_{\lambda}=\varepsilon_{\lambda} .1 . C
$$

Where $A_{\lambda}$ is the absorbance of the solution at a given wavelength $(\lambda), \varepsilon_{\lambda}$ is the molar absorption coefficient at a given wavelength $(\lambda), l$ is the optical path and $\mathrm{C}$ is the concentration of the solution.

Standard clear solutions of $\mathrm{Er}^{3+}$ were prepared by mixing hydrated erbium nitrate and 3-chlorobenzoic acid $\left(\mathrm{Er}^{3+} / \mathbf{3}-\mathbf{c b}^{2-}: 6 / 14\right)$ in a mixture of hexane and aqueous nitric acid 
(7.8 mol. $\mathrm{L}^{-1}$ in water). This allowed the drawing of a calibrating curve $\mathrm{A}_{522 \mathrm{~nm}}=\mathrm{f}\left(\left[\mathrm{Er}^{3+}\right]\right)$. Measurements have been done at $522 \mathrm{~nm}$ absorption wavelength that corresponds to the ${ }^{4} \mathrm{I}_{15 / 2} \rightarrow{ }^{2} \mathrm{H}_{11 / 2}$ Er $^{3+}$ transition. Adding aqueous nitric acid to an hexane solution of $\left\{\mathbf{E r}_{6}(\mathbf{3}-\mathbf{c b})\right\}$ provokes the destruction of the complex and allows the titration of the $\mathrm{Er}^{3+}$ concentration in the solution and consequently of $\left\{\mathbf{E r}_{\mathbf{6}}(\mathbf{3}-\mathbf{c b})\right\}$ in the starting hexane solution (before addition of nitric acid).

By this method we have also measured the molar absorption coefficient of $\left\{\mathbf{E r}_{\mathbf{6}} \mathbf{( 3 - c b )}\right\}$ in hexane at the appropriate wavelength for exciting the ligand ( $\lambda_{\text {exc }}=294 \mathrm{~nm}$ ): $\varepsilon_{(294 \mathrm{~nm})}=1097 \mathrm{~cm}^{-1} \cdot \mathrm{L} \cdot \mathrm{mol}^{-1}$. This sizeable value allows to estimate the concentration of $\left\{\mathbf{L n}_{\mathbf{6}}(\mathbf{3}-\mathbf{c b})\right\}$ in any hexane solution whatever the $\mathrm{Ln}^{3+}$ ion is.

\section{Solid state luminescent measurements.}

Solid state excitation and emission spectra have been measured on a Horiba Jobin-Yvon Fluorolog III fluorescence spectrometer with a Xe lamp. Slit widths for excitation and emission were $2 \mathrm{~nm}$ for the $\mathrm{Eu}$ - and Tb-containing compounds and $5 \mathrm{~nm}$ for the Dy-containing compounds. Luminescence spectra were recorded between $450 \mathrm{~nm}$ and $750 \mathrm{~nm}$ at room temperature. The data were collected at every $1.0 \mathrm{~nm}$ with an integration time of $100 \mathrm{~ms}$ for each step. The quantum yield measurements were performed using a Jobin-Yvon integrating sphere $\left(\Phi=\left(E_{c}-E_{a}\right) /\left(L_{a}-L_{c}\right)\right.$ with $E_{c}$ being the integrated emission spectrum of the sample, $\mathrm{E}_{\mathrm{a}}$ the integrated "blank" emission spectrum, $\mathrm{L}_{\mathrm{a}}$ the "blank" absorption and $\mathrm{L}_{\mathrm{c}}$ the sample absorption at the excitation wavelength). The emission/excitation spectra and quantum yield recordings were realized on crystal samples introduced in cylindrical quartz cells of $0.7 \mathrm{~cm}$ diameter and $2.4 \mathrm{~cm}$ height, which were placed directly inside the integrating sphere. Luminescence decays have also been measured at room temperature using this apparatus with a Xe flash lamp (phosphorescence mode). Appropriate filters were used to remove the 
residual excitation laser light, the Rayleigh scattered light and associated harmonics from spectra. All spectra were corrected for the instrumental response function.

\section{Colorimetric measurements.}

The CIE (Commission Internationale de l'Eclairage) (x,y) emission color coordinates ${ }^{[33-34]}$ were calculated on the basis of emission spectra that have been measured on a Horiba Jobin Yvon Fluorolog III spectrometer under 294 nm excitation.

$\mathrm{X}=k \times \int_{380 \mathrm{~nm}}^{780 \mathrm{~nm}} I_{\lambda} \times x_{\lambda}, \mathrm{Y}=k \times \int_{380 \mathrm{~nm}}^{780 \mathrm{~nm}} I_{\lambda} \times y_{\lambda}$ and $\mathrm{Z}=k \times \int_{380 \mathrm{~nm}}^{780 \mathrm{~nm}} I_{\lambda} \times z_{\lambda}$ with $\mathrm{k}$ constant for the measurement system; $\mathrm{I}_{\lambda}$ sample spectrum intensity, wavelength depending; $\mathrm{x}_{\lambda}, \mathrm{y}_{\lambda}, \mathrm{z}_{\lambda}$ the trichromatic values; $\mathrm{x}=\mathrm{X} /(\mathrm{X}+\mathrm{Y}+\mathrm{Z}), \mathrm{y}=\mathrm{Y} /(\mathrm{X}+\mathrm{Y}+\mathrm{Z})$ and $\mathrm{z}=\mathrm{Z} /(\mathrm{X}+\mathrm{Y}+\mathrm{Z})$. Mean $\mathrm{x} \mathrm{y}$ values are given for each sample, which act as light sources (luminescent samples).

\section{Magnetic measurements}

Static (dc) and dynamic (ac) magnetic measurements have been performed on pellets made of a collection of microcrystals. All measurements were performed with a Quantum Design MPMS magnetometer, corrected from diamagnetic contribution as calculated by Pascal's constants and from the contribution of the sample holder.

\section{RESULTS AND DISCUSSION.}

Oxo-hydroxo hexa-lanthanide complexes are quite sensible to moisture that provokes hydrolysis of the complex and finally leads to insoluble oxy-nitrate polymeric species. ${ }^{[35-38]}$ Moreover, they are very sensitive to acidity: too acidic solutions destroy the oxo-hydroxo complex and simple lanthanide ions are finally obtained while too basic solutions provoke hydrolysis. Therefore, these complexes can only be used as molecular building blocks in non-aqueous solvent and in association with ligands that present neither a too acidic character 
nor a too basic one. 3 -chlorobenzoic acid $\left(\mathrm{pK}_{\mathrm{a}}=3.8\right.$ in water) satisfies these requirements and acetonitrile has proved that it is a suitable organic medium for hexa-lanthanide complexes chemistry. ${ }^{[24]}$

By solvo-thermal synthesis a new series of compounds with general chemical formula $\left\{\left[\mathrm{Ln}_{6}\left(\mu_{3}-\mathrm{OH}\right)_{2}\left(\mathrm{H}_{2} \mathrm{O}\right)_{2}\left(\mathrm{NO}_{3}\right)_{2}(\mathbf{3}-\mathbf{c b})_{14}\right] \cdot\left(\mathrm{CH}_{3} \mathrm{CN}\right)_{4}\right\}\left(\left\{\mathbf{L n}_{\mathbf{6}}(\mathbf{3}-\mathbf{c b})\right\}\right)$ with $\mathrm{Ln}=\mathrm{Eu}, \mathrm{Tb}, \mathrm{Dy}, \mathrm{Ho}, \mathrm{Er}$ plus Y has been obtained. Crystal structure has been solved on the basis of the Dy-containing compound and iso-stucturality of the other compounds of the series has been assumed on the basis of their unit cell determinations.

$\left\{\mathbf{D y}_{\mathbf{6}}(3-\mathbf{c b})\right\}$ crystallizes in the triclinic system, space group $P-1 \quad\left(\mathrm{n}^{\circ} 2\right)$ with the following cell parameters: $a=13.9825(17) \AA, \quad b=16.5065(19) \AA, \quad c=17.3472(18) \AA$, $\alpha=102.844(4)^{\circ}, \beta=108.306(4)^{\circ}, \quad \gamma=111.950(4)^{\circ}, V=3252.7(7) \AA^{3}$ and $Z=2$. The crystal structure is 0D. There are four crystallization $\mathrm{CH}_{3} \mathrm{CN}$ molecules located in the inter-complexes space. These complexes can be described on the basis of a hexa-lanthanide core decorated by fourteen 3-chlorobenzoate ligands. The six $\mathrm{Dy}^{3+}$ ions are almost coplanar (maximum deviation to the mean plan is $0.06 \AA$ ) and only half of them are independent because of an inversion center that is located at the center of the hexagon (Figure 3). This hexagon is constituted by two almost perfect equilateral triangles Dy1-Dy2-Dy3 capped by a $\mu_{3}-\mathrm{OH}^{-}$group that is a reminiscence of the hexa-lanthanide starting complex. The three $\mathrm{Dy}^{3+}$ ions that constitute a triangle are also linked to each other by four bridging carboxylate groups from four 3-chlorobenzoate ligands. Two out of the four carboxylates present the coordination mode I while the two others present coordination mode II (Figure 3). The two triangles are linked together by six 3-chlorobenzoate ligands. Four out of the six act according to coordination mode I and the remaining two according to coordination mode II. 

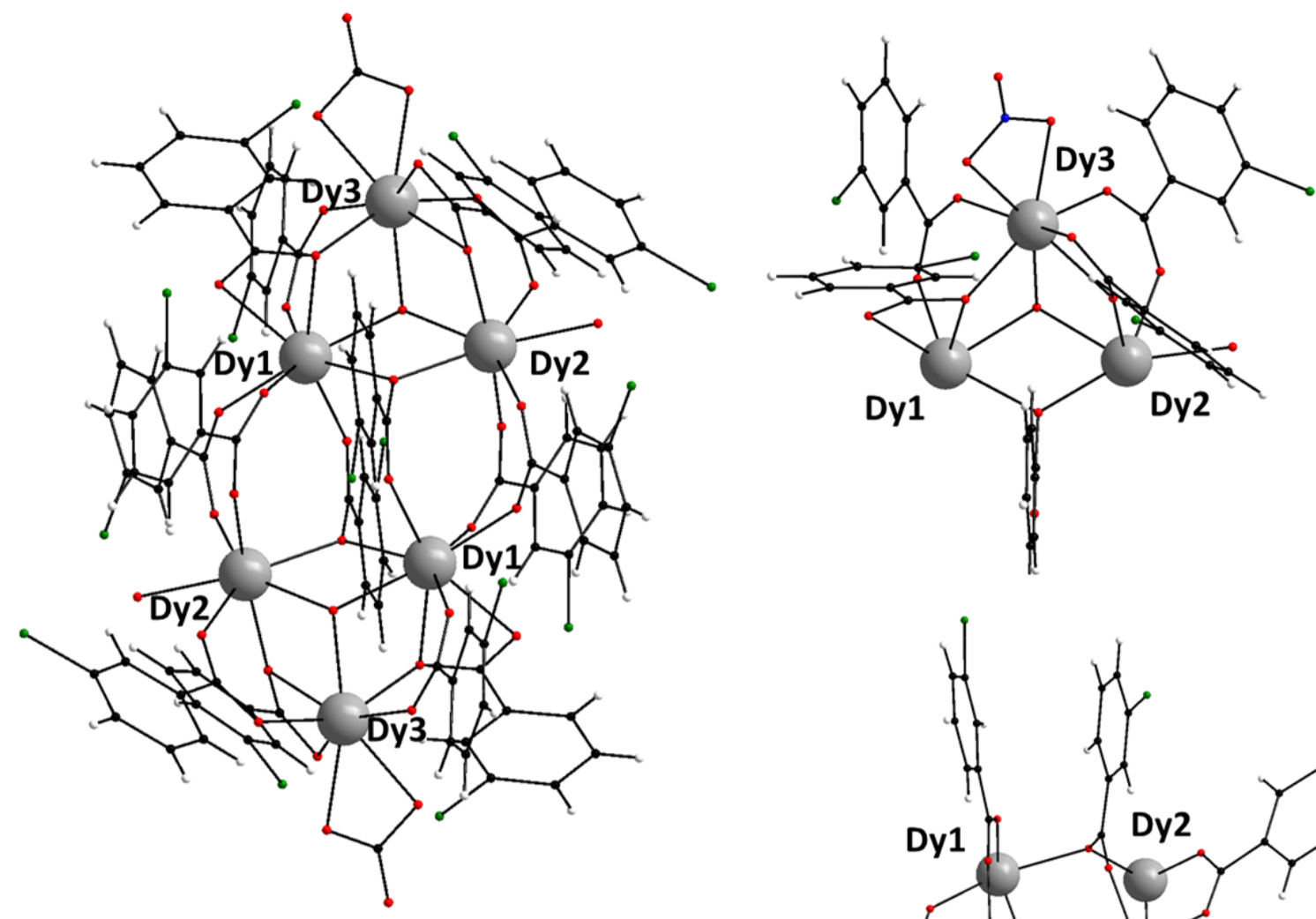

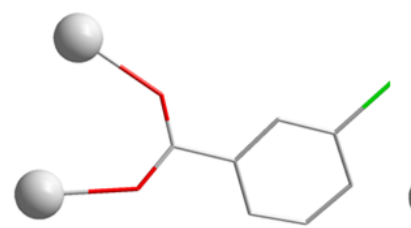

Mode I

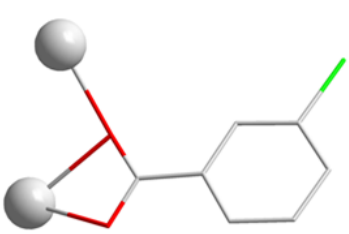

Mode II

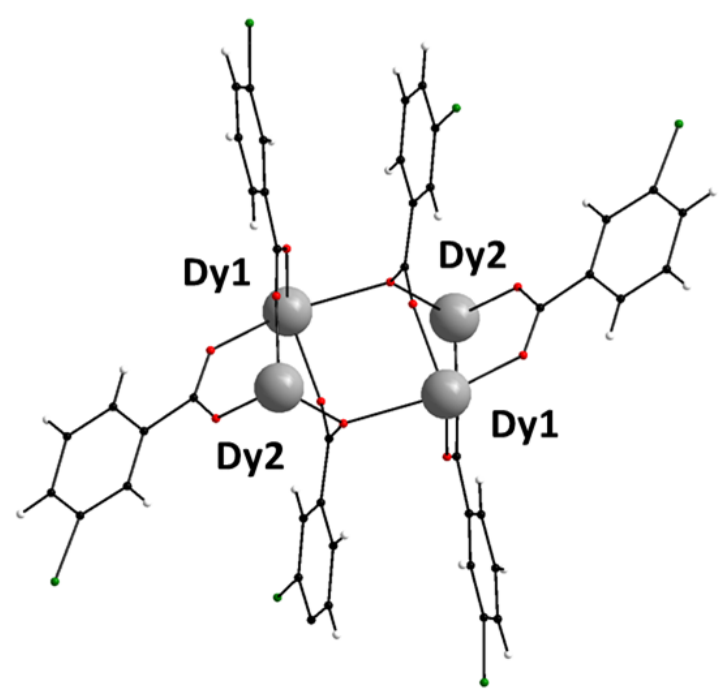

Figure 3. Projection view of the $\left\{\mathbf{D y}_{\mathbf{6}}(\mathbf{3}-\mathbf{c b})\right\}$ complex (top left). Simplified projection view of a tri-nuclear triangle. Only binding ligands have been drawn for clarity. In this motif, the intermetallic distances are: Dy1-Dy2: 3.9602(4) $\AA$; Dy1-Dy3: 3.7726(4) $\AA$; Dy2-Dy3: 3.7631(5) $\AA$ (top right). Simplified projection view of the linkage of the two triangles. Only binding ligands have been drawn for clarity. In this motif intermetallic distances are: Dy1-Dy2: 4.8035(6) $\AA$; Dy1-Dy1: 5.2200(6) $\AA$ (bottom right). Schematic views of the two coordination modes of 3-chlorobenzoate ligand that are encountered in this crystal structure (bottom left).

Dy1 is eight coordinated by seven oxygen atoms from six different 3-chlorobenzoate ligands and one from the capping hydroxo group resulting in a slightly distorted square antiprism. Dy2 is seven coordinated by five oxygen atoms from five different 3-chlorobenzoate ligands, the oxygen atom from the capping hydroxo group and one oxygen atom from a coordination water molecule resulting in a slightly distorted pentagonal-based 
bi-pyramidal. Dy3 is eight coordinated by five oxygen atoms from four different 3-chlorobenzoate ligands, the oxygen atom from the capping hydroxo group and two oxygen atoms from a bidentate nitrate resulting in a slightly distorted square antiprism. It can be noticed that this bidentate nitrate is a reminiscence of the starting hexa-nuclear complex. This has already been observed in previously reported crystal structures. ${ }^{[39]}$

Chloride atoms are located at the periphery of the molecule and the crystal packing is essentially insured by halogen bonds (shortest intermolecular distances $d_{\mathrm{Cl}-\mathrm{Cl}} \simeq 3.9 \AA$ ). These quite large intermolecular contacts can be related to the relatively low calculated density of the compound $\left(1.78\right.$ g.cm $\left.{ }^{-3}\right)$ (Figure 4)

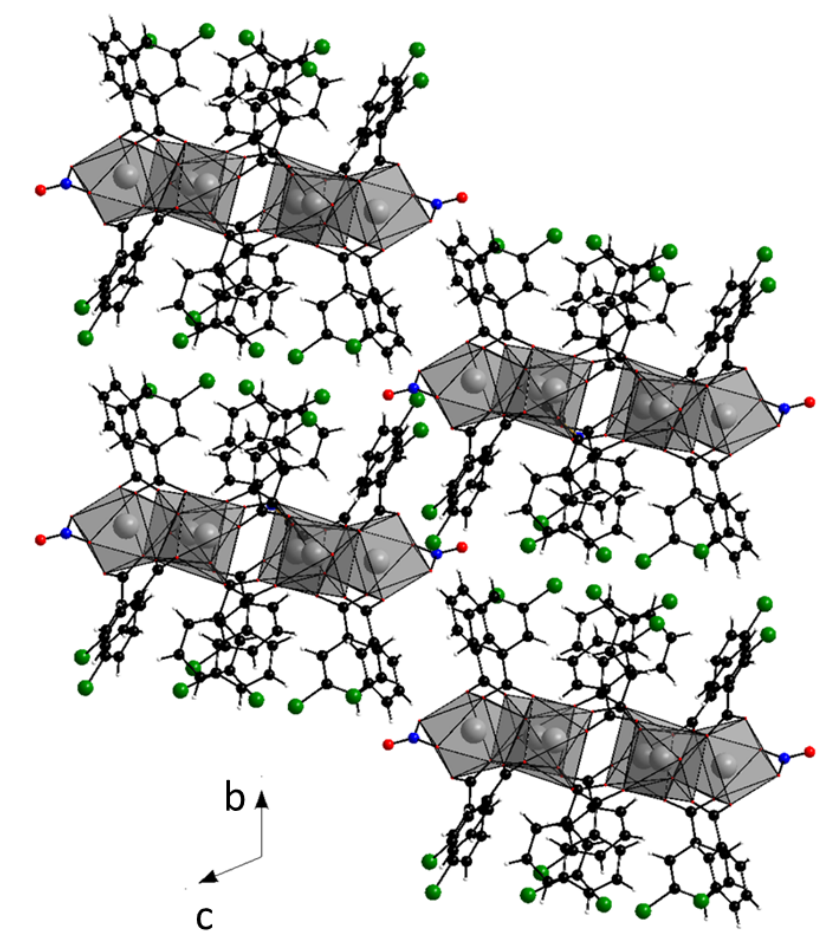

Figure 4. Projection view along the $a$ axis of the crystal packing of $\left\{\mathbf{D y}_{\mathbf{6}}(\mathbf{3}-\mathbf{c b})\right\}$. Crystallization $\mathrm{CH}_{3} \mathrm{CN}$ molecules have been omitted for clarity. Dysprosium coordination polyhedrons have been drawn.

As a consequence, intermetallic distances between lanthanide ions that belong to adjacent molecules are all higher than $10 \AA$ (this value is usually considered as a threshold for efficient intermetallic energy transfers ${ }^{[40]}$ ). 


\section{Magnetic properties of $\left\{\mathrm{Dy}_{6}(3-\mathrm{cb})\right\}$.}

Lanthanides-based molecules are of considerable interest in the field of molecular magnetism. ${ }^{[41-42]}$ Indeed, single-molecule-magnets (SMM) are molecules able to behave as tiny magnets with an hysteretic behavior that has a molecular origin. ${ }^{[43]}$ Their magnetic properties rely on the magnetic anisotropy of their spin carriers and $\mathrm{Dy}^{3+}$ has proven to be one of the most suitable ions to build SMMs. Indeed, a particularly well designed Dy-SMM has been very recently reported and present a breakthrough in the temperature windows at which SMM are efficient, with a molecular magnetic hysteresis that has been observed up to $60 \mathrm{~K}^{[44]}$

In this context, polynuclear Dy-based molecules are of interest as they may be an efficient way to observe magnetic slow relaxation provided that the relative easy magnetic axes of each $\mathrm{Dy}^{3+}$ center is oriented in a tailored direction. ${ }^{[45-46]}$ For example, some of us have shown that if two easy magnetic axes are tilted by $90^{\circ}$ the global magnetic anisotropy of the molecule vanishes. ${ }^{[47]}$ Similarly, if three easy magnetic axes lie in the same plane, toroidal or fully non-collinear magnetic behavior can be observed. ${ }^{[48-50]}$ This make the magnetic analysis of $\left\{\mathbf{D y}_{\mathbf{6}}(\mathbf{3}-\mathbf{c b})\right\}$ worthwhile as it is made of two coplanar and equilateral $\mathrm{Dy}^{3+}$ triangles.

Static (dc) and dynamic (ac) magnetic measurements have been performed on pellets made of a collection of microcrystals. The room temperature value of $\chi_{M} T$ is 82.33 emu.K. $\mathrm{mol}^{-1}$ in agreement with the one of six uncoupled Dy ${ }^{3+}$ ions $\left(g_{j}=4 / 3, J=15 / 2\right.$, $\left.\chi_{\mathrm{M}} \mathrm{T}_{300 \mathrm{~K} \text { theo }}=85.02 \mathrm{emu} . \mathrm{K} \cdot \mathrm{mol}^{-1}\right)$. On lowering the temperature this value decreases to reach 55.83 emu.K. $\mathrm{mol}^{-1}$ at $2 \mathrm{~K}$ (Figure 5). This behavior is characteristic of a thermal depopulation of $\mathrm{Dy}^{3+}$ Stark sub-levels. A very small additional contribution of exchange and/or magnetic dipolar coupling could be expected but its analysis is beyond the scope of this study. At $2 \mathrm{~K}$

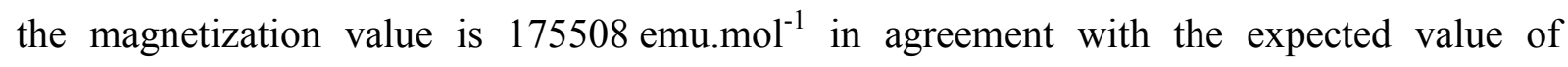
165755 emu.mol ${ }^{-1}$ (Figure 5). 


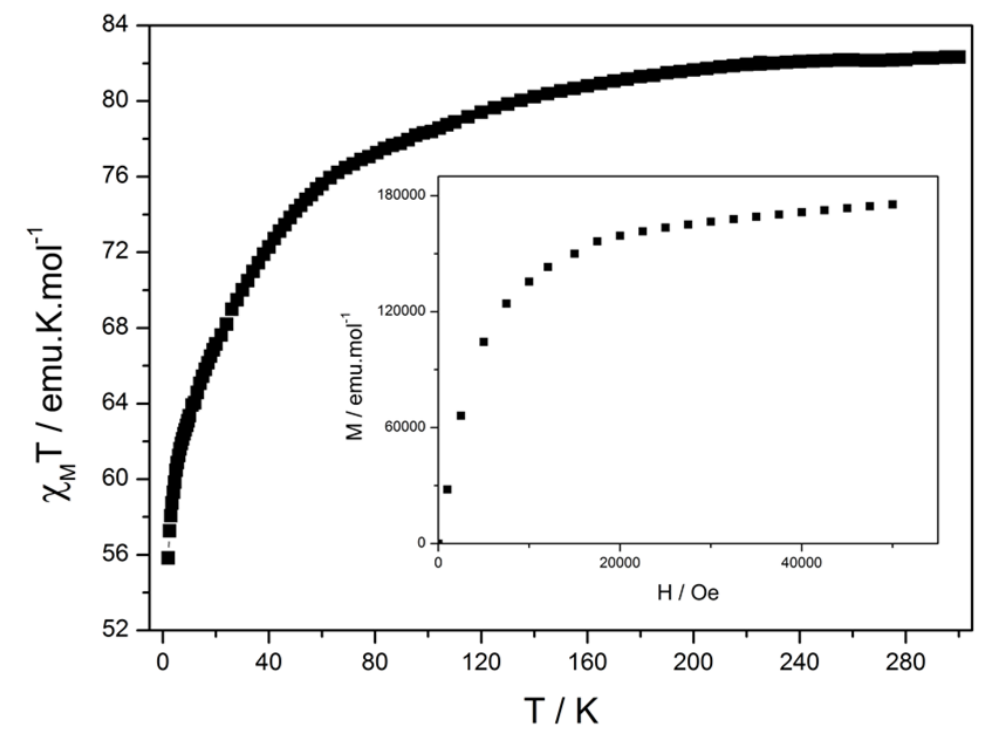

Figure 5. Temperature dependence of $\chi_{M} T$ for $\left\{\mathbf{D y}_{\mathbf{6}}(\mathbf{3}-\mathbf{c b})\right\}$ and field dependence of the magnetization at $2 \mathrm{~K}$ in inset.

Dynamic magnetic measurements have been performed in the absence of static magnetic field $\left(\mathrm{H}_{\mathrm{dc}}=0\right)$ but no significant signal of out-of phase susceptibility $\left(\chi_{\mathrm{M}}\right.$ ") has been observed. This fast relaxation regime can be partially removed by applying a static magnetic field whose optimum value is estimated to be 2400 Oe for a relaxation rate of $150 \mathrm{~Hz}$ at $2 \mathrm{~K}$ (Figure 6). The ratio between the in-phase $\left(\chi_{M}\right)$ and out-of phase $\left(\chi_{M}\right.$ ") susceptibilities is very high (see Figure S2). Temperature dependence of $\chi_{\mathrm{M}}$ " has been measured in these conditions but the relaxation rate remains identical. This indicates that the $\mathrm{H}_{\mathrm{dc}}$ field is not able to promote a significant magnetic slow relaxation and that fast relaxing and temperature independent relaxation is still present. 

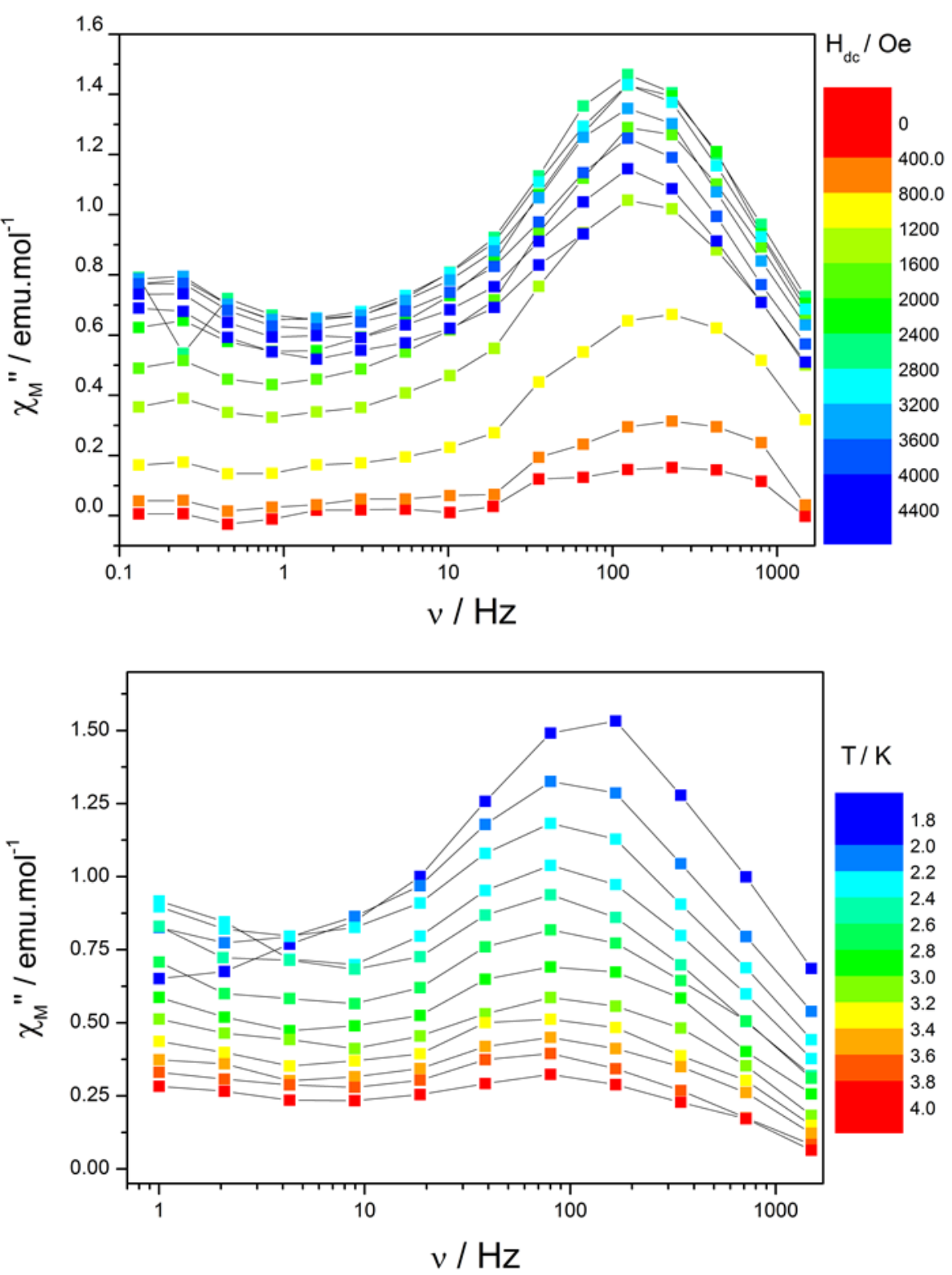

Figure 6. Frequency dependence of $\chi_{M}$ " at $2 \mathrm{~K}$ for various static magnetic fields (top). Frequency dependence of $\chi_{\mathrm{M}}$ " with $\mathrm{H}_{\mathrm{dc}}=2400$ Oe for various temperatures for $\left\{\mathbf{D y}_{\mathbf{6}}(\mathbf{3}-\mathbf{c b})\right\}$ (bottom).

This results is quite disappointing but can be explained by several geometric features of the molecule. First, the three crystallographically independent $\mathrm{Dy}^{3+}$ ions have very different coordination geometries as well as different coordinating modes toward the carboxylate-based ligand. This obviously induces a different electrostatic environment around each magnetic center and cannot induce an optimized magnetic relaxation for each magnetic 
center. Second, if one compares with closely related and previously reported SMMs made of sole $\mathrm{Dy}^{3+}$ triangles ${ }^{[48-50]}$ or coupled $\mathrm{Dy}^{3+}$ triangles ${ }^{[51]}$ several differences are visible. In the SMMs, each triangle possesses two central $\mu_{3}$ oxygen atoms above and below the $\mathrm{Dy}^{3+}$ plane. This constrains the whole surrounding of each $\mathrm{Dy}^{3+}$ ion and induces a toroidal magnetic behavior. In $\left\{\mathbf{D y}_{\mathbf{6}}(\mathbf{3 - c b})\right\}$, only one $\mu_{3}$ oxygen atom is present. This creates an asymmetric electrostatic surrounding around each triangle that is harmful to the SMM behavior.

\section{Solid state optical properties of $\left\{\operatorname{Ln}_{6}(3-c b)\right\}$.}

Solid state excitation and emission spectra have been recorded for $\left\{\mathbf{L n}_{6}(\mathbf{3}-\mathbf{c b})\right\}$ with $\mathrm{Ln}=\mathrm{Eu}, \mathrm{Tb}$ and Dy (Figure 7).
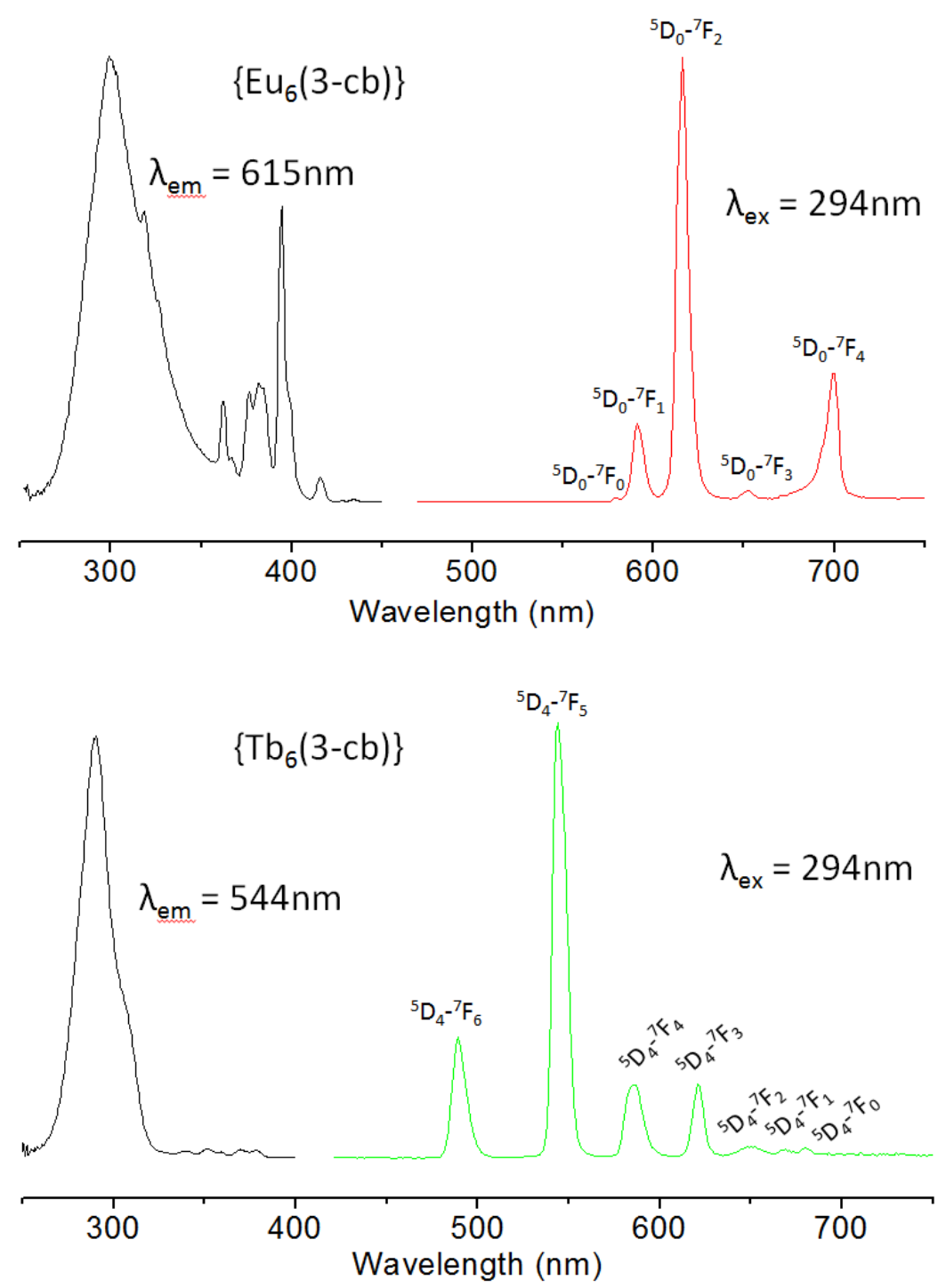


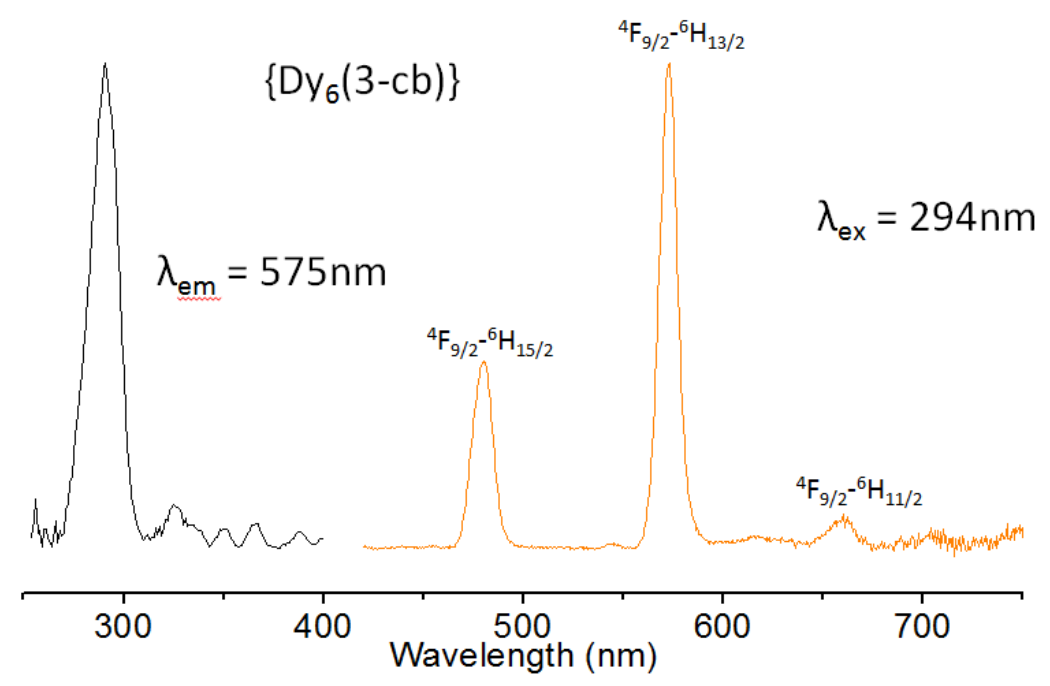

Figure 7. Solid state excitation and emission spectra of $\left\{\mathbf{L n}_{\mathbf{6}}(\mathbf{3 - c b})\right\}$ with $\mathrm{Ln}=\mathrm{Eu}, \mathrm{Tb}$ and $\mathrm{Dy}$ (red, green and orange curves for the emission curves, respectively).

Excitation spectra demonstrate that 3-chlorobenzoate ligand exhibits an efficient antenna effect ${ }^{[52]}$ toward these three lanthanide ions $\left(\lambda_{\mathrm{exc}}=294 \mathrm{~nm}\right)$. Overall quantum yields $\left(Q_{\mathrm{Ln}}^{\mathrm{Ligand}}\right)$ and observed luminescent lifetimes have also been measured. They are listed in Table 3.

Table 3. Overall quantum yields and observed luminescent lifetimes of $\left\{\mathbf{D y}_{\mathbf{6}}(\mathbf{3}-\mathbf{c b})\right\}$ with $\mathrm{Ln}=\mathrm{Eu}, \mathrm{Tb}$ and Dy.

\begin{tabular}{lll}
\hline $\mathrm{Ln}$ & $\mathrm{Q}_{\text {Ligand }}^{\text {Ln }}(\%)$ & $\tau_{\text {obs }}(\mathrm{ms})$ \\
\hline $\mathrm{Eu}$ & $25(3)$ & $0.45(4)$ \\
$\mathrm{Tb}$ & $88(2)$ & $1.16(2)$ \\
$\mathrm{Dy}$ & $4.1(1)$ & $0.21(2)$ \\
\hline
\end{tabular}

Table 3 shows that overall quantum yield and observed luminescent lifetime of the $\mathrm{Dy}^{3+}$-based complex are unusually high for coordination compounds. ${ }^{[8,53]}$ This must be related to the weak number of $\mathrm{O}-\mathrm{H}$ and $\mathrm{C}-\mathrm{H}$ vibrators in the vicinity of lanthanide ions. ${ }^{[1,54]}$ Indeed, there are only two coordination water molecules and two hydroxo groups per hexa-nuclear complex. This can also explain the high values measured for the $\mathrm{Tb}^{3+}$ - and the $\mathrm{Eu}^{3+}$-based complexes. 
Sensitization efficiency $\left(\eta_{\text {sens }}\right)$, is defined as the efficacy with which energy is transferred from the ligand to the lanthanide ion:

$$
Q_{\mathrm{Ln}}^{\text {Ligand }}=\eta_{\text {sens }} Q_{\mathrm{Ln}}^{\mathrm{Ln}}=\eta_{\text {sens }} \frac{\tau_{\text {obs }}}{\tau_{\text {rad }}}
$$

where $\mathrm{Q}_{\mathrm{Ln}}^{\mathrm{Ln}}$ is the intrinsic quantum yield upon direct excitation of the ligand and $\tau_{\text {rad }}$ is the radiative lifetime. ${ }^{[1,55]}$ For Eu-containing compounds a simplified relationship allows the estimation of the radiative lifetime: ${ }^{[56]}$

$$
\frac{1}{\tau_{\mathrm{rad}}}=\mathrm{A}_{\mathrm{MD}, 0} \mathrm{n}\left(\frac{\mathrm{I}_{\mathrm{tot}}}{\mathrm{I}_{\mathrm{MD}}}\right)
$$

Where $\mathrm{A}_{\mathrm{MD}, 0}$ is equal to $14.65 \mathrm{~s}^{-1}$ and corresponds to the spontaneous emission probability of the magnetic dipole ${ }^{5} \mathrm{D}_{0} \rightarrow{ }^{7} \mathrm{~F}_{1}, \mathrm{n}$ is the refractive index and $\mathrm{I}_{\text {tot }}$ and $\mathrm{I}_{\mathrm{MD}}$ are the integrated intensities of the ${ }^{5} \mathrm{D}_{0} \rightarrow{ }^{7} \mathrm{~F}_{\mathrm{J}}(\mathrm{J}=0-6)$ transitions and of the ${ }^{5} \mathrm{D}_{0} \rightarrow{ }^{7} \mathrm{~F}_{1}$ transition only, respectively. Refractive index $\mathrm{n}$ was estimated to 1.50 on the basis of know refractive indexes of similar compounds. ${ }^{[53,57]}$ With these assumptions, one obtains $\tau_{\text {rad }}=1.89 \mathrm{~ms}$ and $\mathrm{Q}_{\mathrm{Ln}}^{\mathrm{Ln}}=24 \%$ for $\left\{\mathbf{E u}_{\mathbf{6}}(\mathbf{3}-\mathbf{c b})\right\}$, which means that $\eta_{\text {sens }}$ is close to $100 \%$ (given the uncertainty on the calculated $\mathrm{Q}_{\mathrm{Ln}}^{\mathrm{Ln}}$ and measured $\mathrm{Q}_{\mathrm{Eu}}^{\mathrm{Ligand}}$ values).

Colorimetric coordinates of the Eu-, Tb- and Dy-based hexa-nuclear complexes under UV-irradiation $\left(\lambda_{\text {exc }}=294 \mathrm{~nm}\right)$ have also been measured (Figure 8). Values are as expected from literature. ${ }^{[58]}$ 


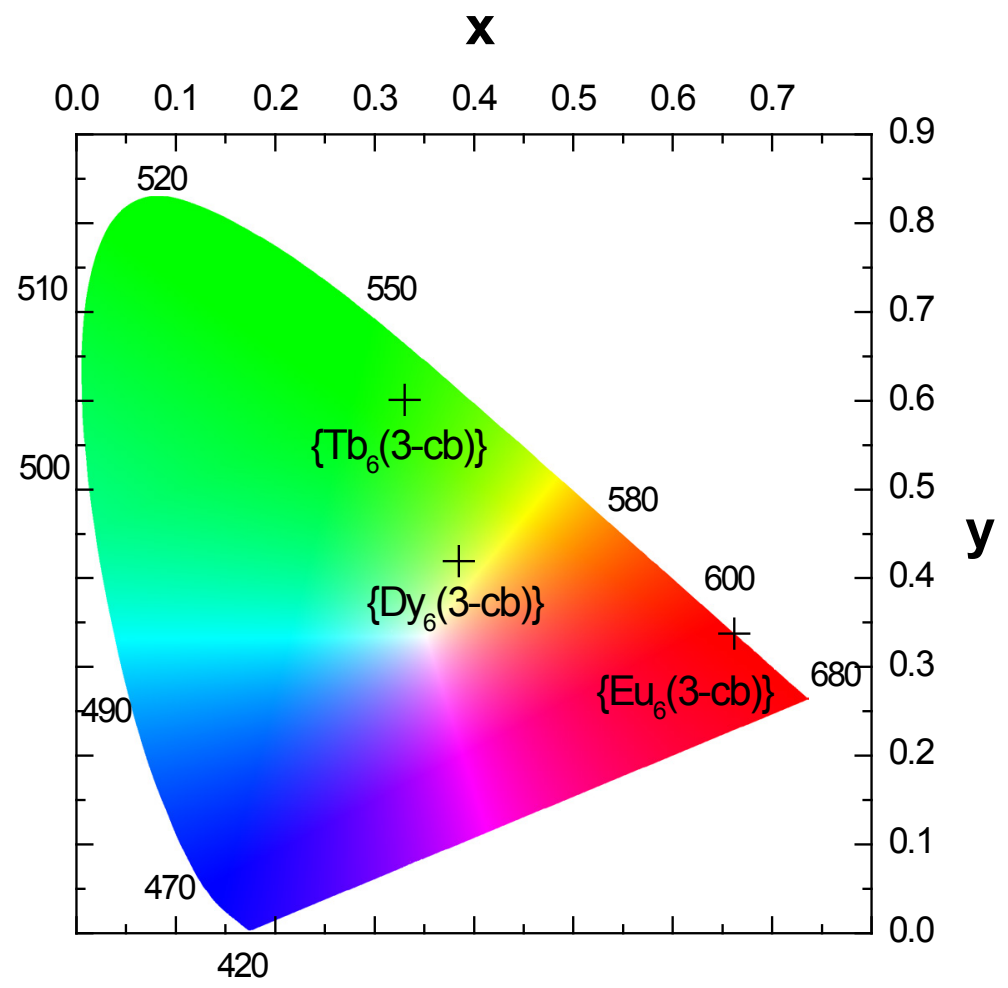

Figure 8. Colorimetric coordinates of $\left\{\mathbf{L n}_{6}(3-\mathbf{c b})\right\}$ with $\mathrm{Ln}=\mathrm{Eu}, \mathrm{Tb}$ and $\mathrm{Dy}$ in the solid state under UV-excitation $\left(\lambda_{\mathrm{exc}}=294 \mathrm{~nm}\right)$.

\section{Hetero-poly-nuclear complexes.}

$$
\left\{[ \mathrm { Eu } _ { 6 } ( \mu _ { 3 } - \mathrm { OH } ) _ { 2 } ( \mathrm { H } _ { 2 } \mathrm { O } ) _ { 2 } ( \mathrm { NO } _ { 3 } ) _ { 2 } ( \mathbf { 3 } - \mathbf { c b } ) _ { 1 4 } ] _ { 1 / 2 } [ \mathrm { Tb } _ { 6 } ( \mu _ { 3 } - \mathrm { OH } ) _ { 2 } ( \mathrm { H } _ { 2 } \mathrm { O } ) _ { 2 } ( \mathrm { NO } _ { 3 } ) _ { 2 } ( \mathbf { 3 } - \mathbf { c b } ) _ { 1 4 } ] _ { 1 / 2 } \cdot \left(\mathrm{CH}_{3} \mathrm{C}\right.\right.
$$

$\left.\mathrm{N})_{4}\right\}$, hereafter symbolized by $\left\{\left[\mathbf{E u}_{\mathbf{6}}(\mathbf{3}-\mathbf{c b})\right]_{\mathbf{0 . 5}}\left[\mathbf{T b}_{\mathbf{6}}(\mathbf{3}-\mathbf{c b})\right]_{\mathbf{0 . 5}}\right\}$, has been prepared from a $50 / 50$ mixture of Eu- and Tb-based molecular octahedral precursors (Scheme 1A). 


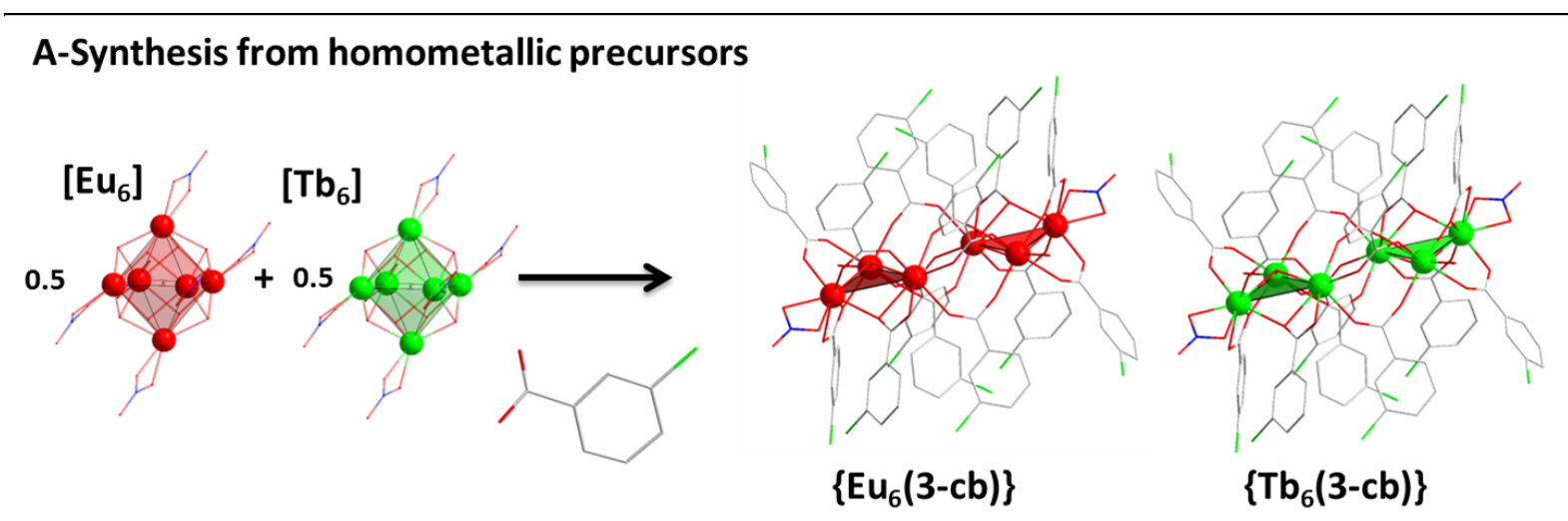

\section{B-Synthesis from heterometallic precursors}
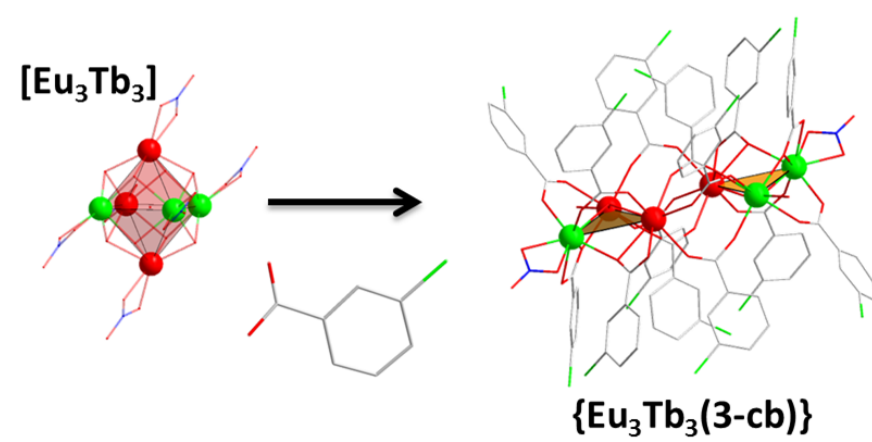

Scheme 1. Schematic representation of the two different modes of synthesis used in this study.

In this compound, statistically, one complex out of two is $\left\{\mathbf{E} \mathbf{u}_{6}(\mathbf{3}-\mathbf{c b})\right\}$ and the other one is $\left\{\mathbf{T b}_{\mathbf{6}}(\mathbf{3}-\mathbf{c b})\right\}$. Unexpectedly, it exhibits, under UV excitation, an orange luminescence in the solid state and its emission spectrum is dominated by emission peaks characteristic of $\left\{\mathbf{E} \mathbf{u}_{6}(\mathbf{3 - c b})\right\}$ (Figure 9). This strongly suggests that despite large intermetallic distances between lanthanide ions that belong to adjacent complexes (higher than $10 \AA$ ), a sizeable inter-metallic transfer between adjacent complexes is observed.

In order to confirm this assumption, we have also prepared the compound $\left\{\left[\mathrm{Y}_{6}\left(\mu_{3}-\mathrm{OH}\right)_{2}\left(\mathrm{H}_{2} \mathrm{O}\right)_{2}\left(\mathrm{NO}_{3}\right)_{2}(\mathbf{3}-\mathbf{c b})_{14}\right]_{0.8}\left[\mathrm{Eu}_{6}\left(\mu_{3}-\mathrm{OH}\right)_{2}\left(\mathrm{H}_{2} \mathrm{O}\right)_{2}\left(\mathrm{NO}_{3}\right)_{2}(\mathbf{3}-\mathbf{c b})_{14}\right]_{0.1}\left[\mathrm{~Tb}_{6}\left(\mu_{3}-\mathrm{OH}\right)_{2}\left(\mathrm{H}_{2}\right.\right.\right.$ $\left.\left.\mathrm{O})_{2}\left(\mathrm{NO}_{3}\right)_{2}(\mathbf{3 - c b})_{14}\right]_{0.1} \cdot\left(\mathrm{CH}_{3} \mathrm{CN}\right)_{4}\right\}, \quad$ hereafter symbolized by $\left\{\left[\mathbf{Y}_{6}(3-\mathbf{c b})\right]_{0.8}\left[\mathbf{E u}_{6}(3-\mathbf{c b})\right]_{0.1}\left[\mathbf{T b}_{6}(3-\mathbf{c b})\right]_{0.1}\right\}$, in which the relative ratio between Eu- and Tb-based complexes is the same than in the previous compound (one to one) but in in which 
Eu- and Tb-based complexes are isolated from each other by optically inert Y-based complexes $^{[8]}$ (Scheme 2).

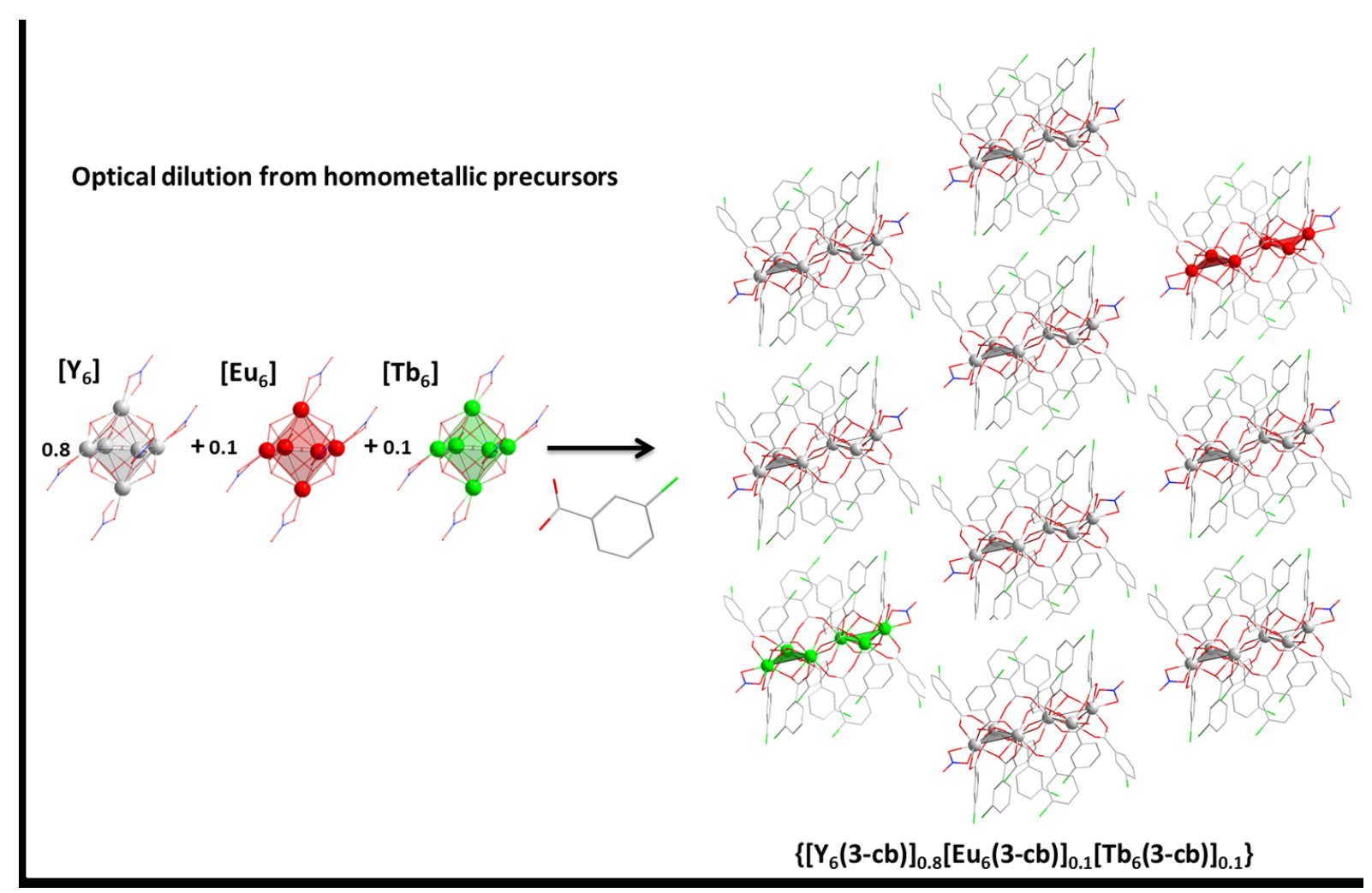

Scheme 2. Schematic representation of $\left\{\left[\mathbf{Y}_{6}(3-c b)\right]_{0.8}\left[\mathbf{E} \mathbf{u}_{6}(3-c b)\right]_{0.1}\left[\mathbf{T b}_{6}(3-c b)\right]_{0.1}\right\}$.

This compound exhibits yellow emission under UV-irradiation and its emission spectra presents both the characteristics features of the emission spectra of $\left\{\mathbf{E} \mathbf{u}_{6}(\mathbf{3}-\mathbf{c b})\right\}$ and $\left\{\mathbf{T b}_{6}(3-\mathbf{c b})\right\}$ (Figure 9). 


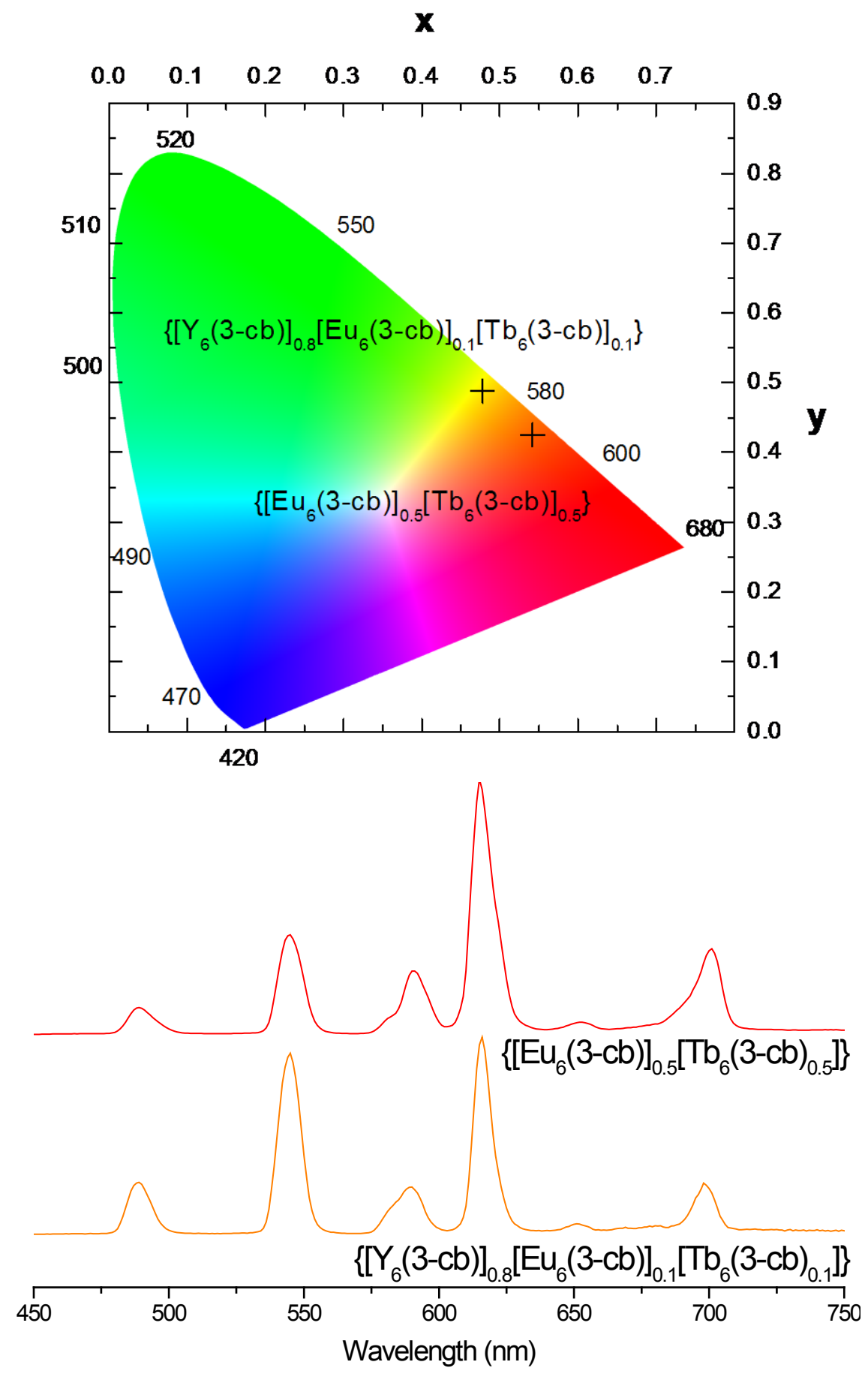

Figure 9. Colorimetric coordinates (top) and emission spectra (bottom) of $\left\{\left[\mathbf{E u}_{6}(3-\mathrm{cb})\right]_{0.5}\left[\mathrm{~Tb}_{6}(\mathbf{3} \mathrm{cb})\right]_{0.5}\right\}$ and $\left\{\left[\mathbf{Y}_{6}(3-\mathrm{cb})\right]_{0.8}\left[\mathbf{E u}_{6}(3-\mathrm{cb})\right]_{0.1}\left[\mathbf{T b} \mathbf{b}_{6}(3-\mathrm{cb})\right]_{0.1}\right\}$ in the solid state under UV-irradiation $\left(\lambda_{\text {exc }}=294 \mathrm{~nm}\right)$. 


\section{Liquid state optical properties of $\left\{\operatorname{Ln}_{6}(3-c b)\right\}$.}

$\left\{\mathbf{L n}_{6}(\mathbf{3}-\mathbf{c b})\right\}$ compounds, that are isolated as single crystals are readily soluble in several solvents such as hexane or heptane at least up to $1 \mathrm{mmol} \cdot \mathrm{L}^{-1}$. Solutions of complexes have thus been prepared (typically 15 to 20 single crystals in $2 \mathrm{~mL}$ of hexane).

Excitation and luminescence spectra have been recorded for solutions in hexane of $\left\{\mathbf{E} \mathbf{u}_{6}(3-\mathbf{c b})\right\}$. They are similar to those measured in the solid state (Figure 10) which suggests that the complexes are not destroyed upon solubilization (since antenna effect is still present). To the best of our knowledge there is no other example of poly-lanthanide oxo-hydroxo complexes that can be solubilized without being destroyed.

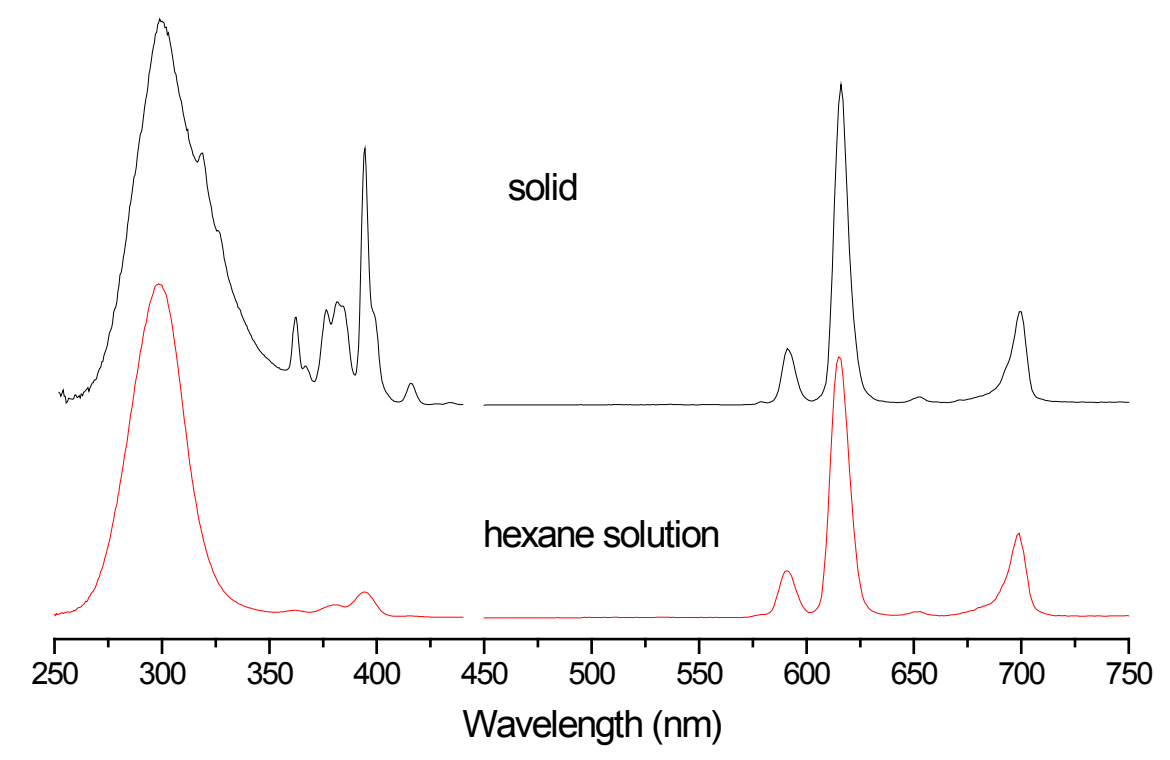

Figure 10. Solid and liquid state (in hexane) excitation and emission spectra of $\left\{\mathbf{E} \mathbf{u}_{\mathbf{6}}(\mathbf{3}-\mathbf{c b})\right\}$.

\section{Investigation of the synthetic process: from $\left[\operatorname{Ln}_{6}\right]$ to $\left\{\operatorname{Ln}_{6}(3-c b)\right\}$.}

It is mandatory to verify if the six lanthanide ions in the final hexa-nuclear complex initially belonged to the same octahedral hexa-nuclear molecular precursor. Indeed, the use of hexa-nuclear complexes as molecular building blocks would present no interest if they were destroyed during the synthetic process. 
Starting oxo-hydroxo complex can be described as a quasi-perfect octahedral with a $\mu_{6}-\mathrm{O}^{2-}$ located at its center and a lanthanide ion at each summit. Each face of the octahedral is capped by a $\mu_{3}-\mathrm{OH}^{-}$group. Each lanthanide ion is nine coordinated by four oxygen atoms from capping $\mathrm{OH}$ - groups, two oxygen atoms from a bidentate nitrate ion, two oxygen atoms from two coordination water molecules and the central $\mu_{6}-\mathrm{O}^{2-}$ ion (Figure 1).

From a geometrical point of view, one can see the synthetic process as a separation and a gliding of two opposite triangular faces of the octahedron. During this process, only one bidentate nitrate, one coordination water molecule and the capping hydroxo group per tri-nuclear fragments remain bound to the lanthanide ion. All the other coordination positions become occupied by oxygen atoms from 3-chlorobenzoate ligands (Scheme 3). It is noticeable that because steric hindrance, coordination numbers of the lanthanide ions decrease.

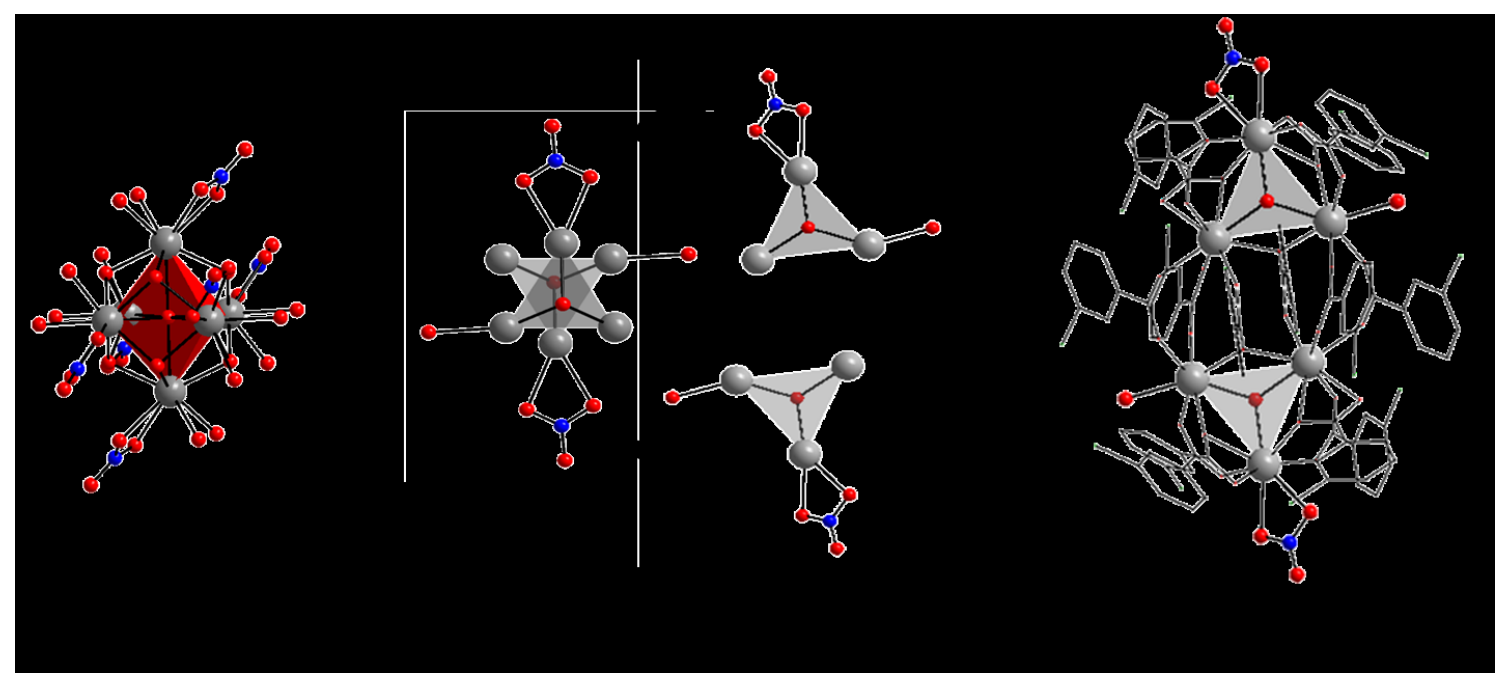

Scheme 3. Suggested mechanism for the formation of $\left\{\mathbf{L n}_{\mathbf{6}}(\mathbf{3}-\mathbf{c b})\right\}$ from $\left[\mathbf{L} \mathbf{n}_{\mathbf{6}}\right]$.

In order to confirm the validity of this model we have prepared two compounds with identical chemical composition: (i) $\left\{\left[\mathbf{E} \mathbf{u}_{\mathbf{6}}(\mathbf{3}-\mathbf{c b})\right]_{\mathbf{0 . 5}}\left[\mathbf{T b}_{\mathbf{6}}(\mathbf{3}-\mathbf{c b})\right]_{\mathbf{0 . 5}}\right\}$ obtained by mixing $\left[\mathbf{E} \mathbf{u}_{6}\right]$

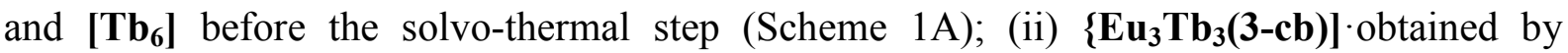
preparing an hetero-lanthanide hexa-nuclear molecular building block $\left[\mathrm{Eu}_{3} \mathrm{~Tb}_{3}\left(\mu_{6}-\mathrm{O}\right)\left(\mu_{3}-\mathrm{OH}\right)_{8}\left(\mathrm{NO}_{3}\right)_{6}\left(\mathrm{H}_{2} \mathrm{O}\right)_{12}\right] \cdot 2 \mathrm{NO}_{3} \cdot 2 \mathrm{H}_{2} \mathrm{O}^{[23]}$ that is $\left[\mathbf{E u}_{3} \mathbf{T b}_{3}\right]$ (Scheme 1B). In order to avoid inter-molecular inter-metallic energy transfers that are present in the solid state, 
both compounds have been dissolved in hexane. Colorimetric coordinates and emission spectra of both solutions have been recorded. They are different (Figure 11): first solution emits orange light $(x=0.62(1) ; y=0.37(1))$ when exposed to UV-radiation $\left(\lambda_{\mathrm{exc}}=294 \mathrm{~nm}\right)$ and its emission spectrum presents the characteristic transitions of both $\mathrm{Eu}^{3+}$ and $\mathrm{Tb}^{3+}$ ions while second solution emits red light $(\mathrm{x}=0.42(1), \mathrm{y}=0.051(1))$ and characteristic transitions of $\mathrm{Eu}^{3+}$ ions clearly dominate the spectrum. This demonstrates that composition of the hexanuclear precursors is preserved upon the synthetic process of planar hexa-lanthanides complexes. To the best of our knowledge, this has never been reported before.

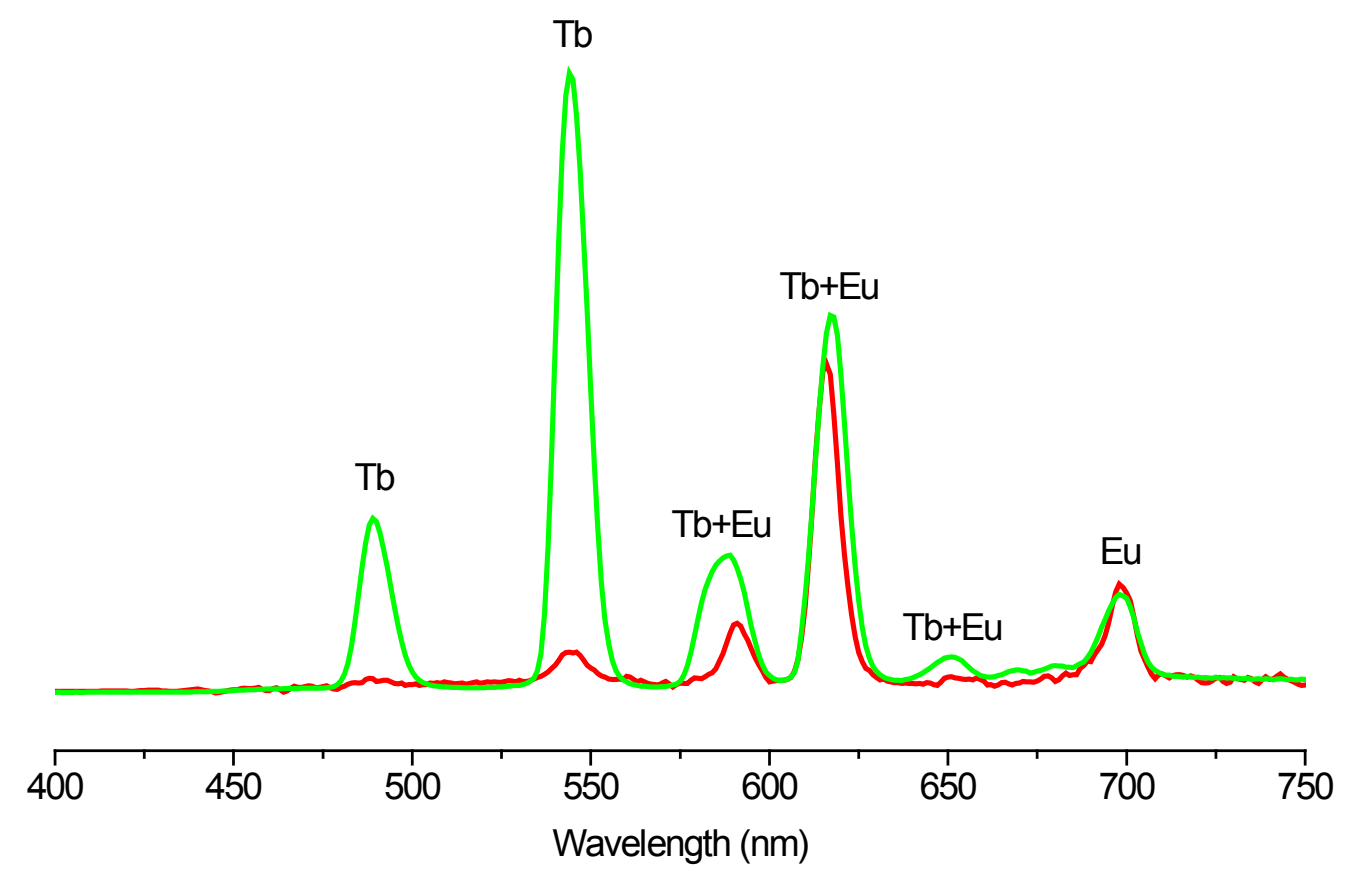

Figure 11. Emission spectra of dilute solutions in hexane (Concentration; $\mathrm{C}=0.2 \mathrm{mmol} . \mathrm{L}^{-1}$ ) of $\left\{\left[\mathbf{E} \mathbf{u}_{\mathbf{6}}(\mathbf{3}-\mathbf{c b})\right]_{\mathbf{1} / 2}\left[\mathbf{T} \mathbf{b}_{\mathbf{6}}(\mathbf{3}-\mathbf{c b})\right]_{\mathbf{1} / 2}\right\}$ (green curve) and $\left\{\left[\mathbf{E} \mathbf{u}_{\mathbf{3}} \mathbf{T} \mathbf{b}_{\mathbf{3}}(\mathbf{3}-\mathbf{c b})\right]\right\}$ (red curve) under UV-irradiation $\left(\lambda_{\mathrm{exc}}=294 \mathrm{~nm}\right)$. Symbols on the spectra indicate the lanthanide ion to which is attributed a given peak (each band can be assigned whether at only Eu(III) transition, or only $\mathrm{Tb}(\mathrm{III})$ transition or a mixture of $\mathrm{Eu}(\mathrm{III})$ and $\mathrm{Tb}(\mathrm{III})$ transitions).

\section{CONCLUSION AND OUTLOOK.}

To the best of our knowledge, compounds that are described herein constitute the first example of poly-lanthanide complexes obtained from isolated poly-lanthanide molecular 
building blocks. These poly-lanthanide molecular building blocks are synthesized and characterized first, and then are used as chemical precursors for the synthesis of the new poly-lanthanide complexes described in this publication. This open the way for the synthesis of new poly-lanthanide complexes with controlled poly-nuclear cores composition. Hetero-lanthanide molecular building blocks have been used instead of homo-lanthanide ones, to lead to new complexes with original optical properties. The photo-physical characterizations have been realized on these homo- and poly-nuclear complexes, opening an approach to understanding the mechanisms that regulate the luminescence properties. This could present a great interest for example for studying $4 \mathrm{f}-4 \mathrm{f}$ ' intermetallic energy transfers or as an application as far as new more efficient taggants for fight against counterfeiting are needed. ${ }^{[59]}$

\section{ACKNOWLEDGEMENTS.}

The China Scholarship Council Ph.D program is acknowledged for financial support. Center of Diffraction of the University of Rennes is acknowledged for single-crystal X-ray diffraction data collection. Thierry Guizouarn and Centre de Mesures Physiques - ISCR are acknowledged for magnetic measurements.

\section{GRAPHICAL ABSTRACT}

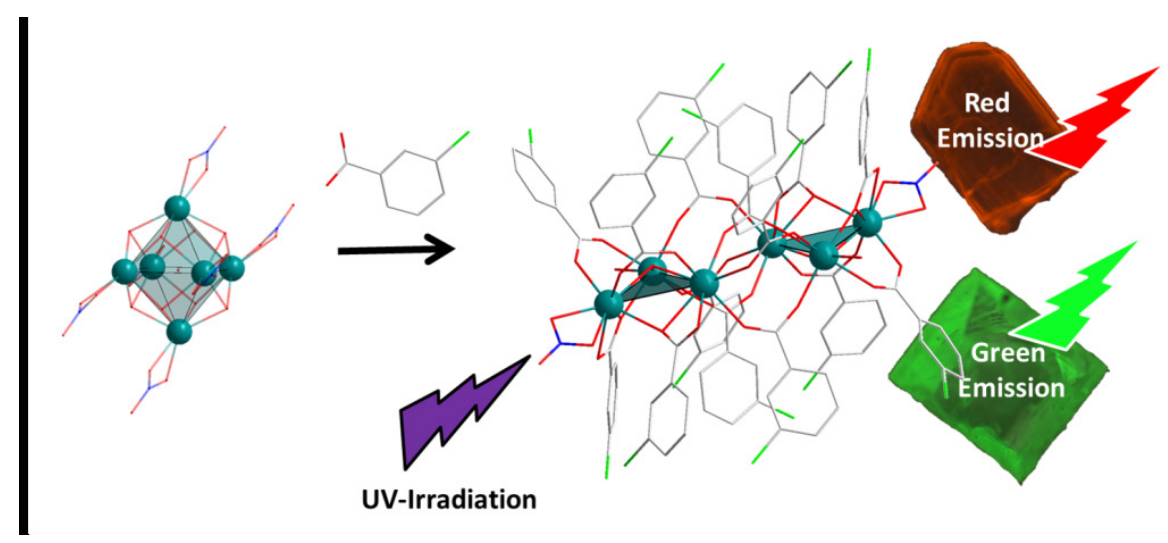




\section{TOC SYNOPSYS.}

Reaction of hexa-nuclear octahedral molecular precursors with 3-chlorobenzoate ligand affords an unprecedented family of iso-structural poly-lanthanide complexes with general

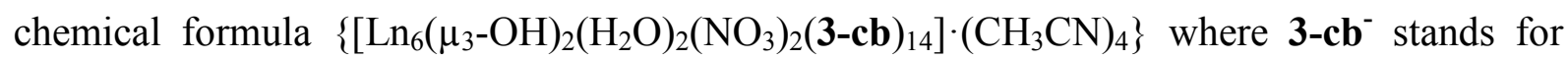
3-chlorobenzoate and $\mathrm{Ln}=\mathrm{Eu}, \mathrm{Tb}, \mathrm{Dy}, \mathrm{Ho}, \mathrm{Er}$ plus Y. Crystal structure, solubility, magnetic and luminescent properties of these complexes have been studied. Luminescence properties evidence that the composition of the hexa-lanthanide precursor is preserved upon the synthetic process.

\section{REFERENCES}

1. Comby, S.; Bünzli, J. C. G.; Gschneider, K. A.; Pecharsky, V. K., Lanthanide Near-Infrared Luminescence in Molecular Probes and Devices. In Handbook on the Physics and Chemistry of Rare Earths, Elsevier: Amsterdam, 2007; Vol. 37, pp 1-353.

2. Bünzli, J.-C. G., Lanthanide luminescence for biomedical analyses and imaging. Chem. Rev. 2010, 111, 2729-2755.

3. Cui, Y.; Li, B.; He, H.; Zhou, W.; Chen, B.; Qian, G., Metal-organic frameworks as platforms for functionnal materials. Accounts Chem. Res. 2016, 49, 483-493.

4. Li, X.-Y.; Shi, W.-J.; Wang, X.-Q.; Ma, L.-N.; Hou, L.; Wang, Y.-Y., Luminescence modulation, white light emission and energy transfer in a family of lanthanide Metal-Organic Frameworks based on a planar $\pi$-conjugated ligand. Cryst. Growth Des. 2017, 17, 4217-4224.

5. You, H.; Fang, J.; Xuan, Y.; Ma, D., Highly efficient red electroluminescence from stacked organic light emitting devices based on europium complexes. Mater. Sci. Eng. B 2006, 131 (1-3), 252255.

6. Binnemans, K., Lanthanide based luminescent hybrid materials. Chem. Rev. 2009, 109 (9), 4283-4374.

7. Guillou, O.; Daiguebonne, C.; Calvez, G.; Bernot, K., A long journey in lanthanide chemistry : from fundamental crystallogenesis studies to commercial anti-counterfeiting taggants. Accounts Chem. Res. 2016, 49, 844-856.

8. Freslon, S.; Luo, Y.; Daiguebonne, C.; Calvez, G.; Bernot, K.; Guillou, O., Brightness and color tuning in a series of lanthanide-based coordination polymers with benzene 1,2,4,5-tetracarboxylic acid as ligand. Inorg. Chem. 2016, 55, 794-802.

9. Desreux, J. F., In Lanthanide Probes in Life, Chemical and Earth Sciences, Choppin, G. R.; Bünzli, J. C. G., Eds. Elsevier: Amsterdam, 1989; Vol. Elsevier, p 43.

10. Karraker, D. G., Coordination of trivalent lanthanide ions. J. Chem. Educ. 1970, 47 (6), 424430.

11. Daiguebonne, C.; Kerbellec, N.; Guillou, O.; Bünzli, J. C. G.; Gumy, F.; Catala, L.; Mallah, T.; Audebrand, N.; Gérault, Y.; Bernot, K.; Calvez, G., Structural and luminescent properties of microsized and nano-sized particles of lanthanide terephthalate coordination polymers. Inorg. Chem. 2008, 47 (9), 3700-3708

12. Kerbellec, N.; Catala, L.; Daiguebonne, C.; Gloter, A.; Stephan, O.; Bünzli, J. C. G.; Guillou, O.; Mallah, T., Luminescent Coordination Nanoparticles. New J. Chem. 2008, 32, 584-587. 
13. Lemonnier, J.-F.; Guénée, L.; Beuchat, C.; Wesolowski, T. A.; Mukherjee, P.; Waldeck, D. H.; Gogick, K. A.; Petoud, S.; Piguet, C., Optimizing sensitization processes in dinuclear luminescent lanthanide oligomers : Selection of rigid aromatic spacers. J. Am. Chem. Soc. 2011, 133, 16219-16234. 14. Eddaoudi, M.; Kim, J.; Rosi, N.; Vodak, D.; Wachter, J.; O'Keeffe, M.; Yaghi, O. M., Systematic Design of Pore Size and Functionnality in Isoreticular MOFs and their application in Methane Storage. Science 2002, 295, 469-472.

15. Deng, H.; Doonan, C. J.; Furukawa, H.; Ferreira, R. B.; Towne, J.; Knobler, C. B.; Wang, B.; Yaghi, O. M., Multiple functional groups of varying ratios in metal-organic Frameworks. Science 2010, 327, 846-850.

16. Fenske, D.; Zhu, N.; Langetepe, T., Synthesis and structure of new Ag-Se clusters. Angew. Chem. Int. Ed. 1998, 37 (19), 2640-2644.

17. Müller, A.; Krickemeyer, E.; Bögge, H.; Schmidtmann, M.; Peters, F., Organizational forms of matter : an inorganic super fullerene and keplerate based on molybdenum oxide. Angew. Chem. Int. Ed. 1998, 37 (24), 3360-3363.

18. Mahé, N.; Guillou, O.; Daiguebonne, C.; Gérault, Y.; Caneschi, A.; Sangregorio, C.; ChaneChing, J. Y.; Car, P. E.; Roisnel, T., Polynuclear Lanthanide Hydroxo Complexes : New Chemical Precursors for Coordination Polymers. Inorg. Chem. 2005, 44 (22), 7743-7750.

19. Calvez, G.; Le Natur, F.; Daiguebonne, C.; Bernot, K.; Suffren, Y.; Guillou, O., Lanthanide-based hexanuclear complexes and their use as molecular precursors. Coord. Chem. Rev. 2017, 340, 134-153. 20. Alezi, D.; Peedikakkal, A. M. P.; Weselinski, L.; Guillerm, V.; Belmabkhout, Y.; Cairns, A. J.; Chen, Z.; Wojtas, L.; Eddaoudi, M., Quest for highly connected metal-organic framework platforms : rara earth polynuclear clusters versatility meets net topology needs. J. Am. Chem. Soc. 2015, 137, 5421-5430.

21. Zheng, Z., Cluster Compounds of Rare-Earth Elements. In Hanbook on the Physics and Chemistry of Rare Earths, Gschneidner, K. A.; Bünzli, J. C. G.; Pecharsky, V. K., Eds. Elsevier: 2010; Vol. 40, pp 109-239.

22. Le Natur, F.; Calvez, G.; Guéguan, J. P.; Le Polles, L.; Trivelli, X.; Bernot, K.; Daiguebonne, C.; Neaime, C.; Costuas, K.; Grasset, F.; Guillou, O., Characterization and luminescence properties of lanthanide based polynuclear complexes nanoaggregates. Inorg. Chem. 2015, 54, 6043-6054.

23. Le Natur, F.; Calvez, G.; Daiguebonne, C.; Guillou, O.; Bernot, K.; Ledoux, J.; Le Polles, L.; Roiland, C., Coordination polymers based on hexanuclear rare earth complexes : Toward independant luminescence brightness and color emission. Inorg. Chem. 2013, 52, 6720-6730.

24. Calvez, G.; Daiguebonne, C.; Guillou, O., Unprecedented lanthanide containing coordination polymers constructed from hexanuclear molecular building blocks : $\{[\mathrm{Ln} 6 \mathrm{O}(\mathrm{OH}) 8](\mathrm{NO} 3) 2$ (bdc)(Hbdc)2,2NO3,H2bdc $\}$ n. Inorg. Chem. 2011, 50, 2851-2858.

25. Zak, Z.; Unfried, P.; Giester, G., The structures of some rare earth basic nitrates [Ln 6 (æ 6 O)(æ $3-\mathrm{OH}) 8$ (H 2 O) 12 (NO 3 ) 6 ] (NO 3 ) 2 .xH 2 O, $\mathrm{Ln}=\mathrm{Y}, \mathrm{Gd}, \mathrm{Yb} ; \mathrm{x}(\mathrm{Y}, \mathrm{Yb})=4, \mathrm{x}(\mathrm{Gd})=5$. A novel rare earth metal cluster of the M 6 X 8 type with interstitial O atom. J. Alloys Compd. 1994, 205, 235-242.

26. Calvez, G.; Daiguebonne, C.; Guillou, O.; Pott, T.; Méléard, P.; Le Dret, F., Lanthanide-based hexanuclear complexes usable as molecular precursor for new hybrid materials : state of the art. C. $R$. Chimie 2010, 13 (6-7), 715-730.

27. Inc., B. A. SAINT, V837A; Brucker: Madison, Wisconsin, USA, 2014.

28. Inc, B. A. SADABS, 2014/5; Bruker: Madison, Wisconsin, USA, 2014.

29. Inc, B. A. APEX3, Bruker: Madison, Wisconsin, USA, 2015.

30. Altomare, A.; Burla, M. C.; Camalli, M.; Carrozzini, B.; Cascarano, G.; Giacovazzo, C.; Guagliardi, A.; Moliterni, A. G. G.; Polidori, G.; Rizzi, A. C., EXPO: a program for full powder pattern decomposition and crystal structure solution. J. Appl. Crystallogr. 1999, 32, 339-340.

31. Sheldrick, G. M.; Schneider, T. R., SHELXL : High-Resolution Refinement. Macromol. Crystallogr. B 1997, 319-343.

32. Farrugia, L. J., WinGX and ORTEP for Windows: an update. J. Appl. Crystallogr. 2012, 45, 849854. 
33. Wyszecki, G., Colorimetry. In Handbook of Optics, Driscoll, W. G.; Vaughan, W., Eds. Mac Graw-Hill Book Company: New-York, 1978; pp 1-15.

34. CIE, International Commission on Illumination - Technical report. CIE: 1995; Vol. 13-3, p 16.

35. Unfried, P.; Rossmanith, K., The chemical decomposition of rare earth nitrates : a new method for the enricment of heavy yttrium earth nitrates in kg-quantities. Monatsh. Chem. 1992, $123,1-8$.

36. Unfried, P.; Rossmanith, K.; Blaha, H., Two new basic Yttrium nitrates. Monatsh. Chem. 1991, 122, 635-644.

37. Pelloquin, D.; Louër, D.; Louër, M., Powder diffraction studies in the YONO3-Y2O3 system. J. Solid State Chem. 1994, 112, 182-188.

38. Beal, G. W.; Milligan, W. O.; Dillin, D. R.; Williams, R. J.; Mc Coy, J. J., Refinement of Neodymium trihydroxide. Acta Crystallogr. B 1976, 32, 2227-2229.

39. Calvez, G.; Bernot, K.; Guillou, O.; Daiguebonne, C.; Caneschi, A.; Mahé, N., Sterically-induced synthesis of $3 \mathrm{~d}-4 \mathrm{f}$ one-dimensional compounds: a new route towards $3 \mathrm{~d}-4 \mathrm{f}$ Single Chain Magnets. Inorg. Chim. Acta 2008, 361, 3997-4003.

40. Bünzli, J. C. G.; Eliseeva, S. V., Basics of lanthanide photophysics. In Lanthanide Luminescence, Hänninen, P.; Härmä, H., Eds. Springer Berlin Heidelberg: 2010; pp 1-45.

41. Sorace, L.; Benelli, C.; Gatteschi, D., Lanthanides in molecular magnetism: old tools in a new field. Chemical Society Reviews 2011, 40 (6), 3092-3104.

42. Woodruff, D. N.; Winpenny, R. E. P.; Layfield, R. A., Lanthanide Single-Molecule Magnets. Chem Rev 2013, 113, 5110-5148.

43. Benelli, C.; Gatteschi, D., Introduction to Molecular Magnetism: From Transition Metals to Lanthanides. Wiley: 2015.

44. Goodwin, C. A. P.; Ortu, F.; Reta, D.; Chilton, N. F.; Mills, D. P., Molecular magnetic hysteresis at 60 kelvin in dysprosocenium. Nature 2017, 548 (7668), 439-442.

45. Bernot, K.; Luzon, J.; Caneschi, A.; Gatteschi, D.; Sessoli, R.; Bogani, L.; Vindigni, A.; Rettori, A.; Pini, M. G., Spin canting in a Dy-based single-chain magnet with dominant next-nearest-neighbor antiferromagnetic interactions. Phys. Rev. B 2009, 79 (13), 134419.

46. Bernot, K.; Luzon, J.; Sessoli, R.; Vindigni, A.; Thion, J.; Richeter, S.; Leclercq, D.; Larionova, J.; van der Lee, A., The canted antiferromagnetic approach to single-chain magnets. J. Am. Chem. Soc. 2008, 130 (5), 1619-1627.

47. Pointillart, F.; Bernot, K.; Sessoli, R.; Gatteschi, D., Effects of 3d-4f magnetic exchange interactions on the dynamics of the magnetization of Dy-III-M-II-Dy-III trinuclear clusters. Chemistry-a European Journal 2007, 13 (5), 1602-1609.

48. Luzon, J.; Bernot, K.; Hewitt, I. J.; Anson, C. E.; Powell, A. K.; Sessoli, R., Spin Chirality in a Molecular Dysprosium Triangle: The Archetype of the Noncollinear Ising Model. Phys. Rev. Lett. 2008, 100 (24), 247205.

49. Chibotaru, L. F.; Ungur, L.; Soncini, A., The origin of nonmagnetic Kramers doublets in the ground state of dysprosium triangles: Evidence for a toroidal magnetic moment. Angew. Chem.-Int. Edit. 2008, 47 (22), 4126-4129.

50. Tang, J. K.; Hewitt, I.; Madhu, N. T.; Chastanet, G.; Wernsdorfer, W.; Anson, C. E.; Benelli, C.; Sessoli, R.; Powell, A. K., Dysprosium triangles showing single-molecule magnet behavior of thermally excited spin states. Angew. Chem.-Int. Edit. 2006, 45 (11), 1729-1733.

51. Lin, S. Y.; Wernsdorfer, W.; Ungur, L.; Powell, A. K.; Guo, Y. N.; Tang, J. K.; Zhao, L.; Chibotaru, L. F.; Zhang, H. J., Coupling Dy-3 Triangles to Maximize the Toroidal Moment. Angew. Chem.-Int. Edit. 2012, 51 (51), 12767-12771.

52. Weissman, S. I., Intramolecular energy transfer - The fluorescence of complexes of europium. J. Chem Phys 1942, 10 (4), 214-217.

53. Haquin, V.; Etienne, M.; Daiguebonne, C.; Freslon, S.; Calvez, G.; Bernot, K.; Le Polles, L.; Ashbrook, S. E.; Mitchell, M. R.; Bünzli, J. C. G.; Guillou, O., Color and Brightness tuning in heteronuclear laanthanide teraphthalate coordination polymers. Eur. J. Inorg. Chem. 2013, 3464-3476. 
54. Bünzli, J. C. G.; Chauvin, A. S.; Kim, H. K.; Deiters, E.; Eliseeva, S. V., Lanthanide luminescence efficiency in eight- and nine-coordinate complexes: Role of the rediative lifetime. Coord. Chem. Rev. 2010, 254 (21-22), 2623-2633.

55. Werts, M. H. V.; Jukes, R. T. F.; Verhoeven, J. W., The emission spectrum and the radiative lifetime of Eu3+ in lanthanide luminescent complexes. Phys Chem Chem Phys 2002, 4, 1542-1548.

56. Chauvin, A. S.; Gumy, F.; Imbert, D.; Bünzli, J. C. G., Europium and terbium tris(dipicolinate) as secondary standards for quantum yield determination. Spectrosc Lett 2004, 37 (5), 512-532.

57. Freslon, S.; Luo, Y.; Calvez, G.; Daiguebonne, C.; Guillou, O.; Bernot, K.; Michel, V.; Fan, X., Influence of photo-induced electron transfer on lanthanide-based coordination polymers luminescence : A comparison between two pseudo-isoreticular molecular networks. Inorg. Chem. 2014, 53, 1217-1228.

58. Eliseeva, S. V.; Bünzli, J. C. G., Rare earths : jewels for functionnal materials of the future. New J. Chem. 2011, 35, 1165-1176.

59. Calvez, G.; Le Natur, F.; Guillou, O. Procédé de marquage d’au moins un matériau comprenant une matrice solide ou liquide, organique ou minérale, et matériau correspondant. French patent FR2995316-A1, 2013. 